\title{
É Atrativo tornar-se Professor do Ensino Médio no Brasil ? Evidências com Base em Decomposições Paramétricas e Não Paramétricas
}

\author{
Ariana Martins de Britto \\ Doutoranda em Economia - Universidade Federal Fluminense (UFF) \\ Endereço: Rua Prof. Marcos Waldemar de Freitas Reis s/nº, bloco F - Campus do Gragoatá, \\ Niterói - RJ - Brasil, CEP: 24210-000 - E-mail: arianabritto@hotmail.com
}

\author{
Fábio D. Waltenberg \\ Professor - Universidade Federal Fluminense (UFF) \\ Endereço: Rua Prof. Marcos Waldemar de Freitas Reis s/nº, bloco F - Campus do Gragoatá, \\ Niterói - RJ - Brasil, CEP: 24210-000 - E-mail: waltenberg@economia.uff.br
}

Recebido em 10 de setembro de 2012. Aceito em 01 de outubro de 2013.

\section{Resumo}

Neste artigo avalia-se a atratividade da ocupação de professor do Ensino Médio, tal como expressa por diferenciais salariais entre essa categoria de professores e três grupos de comparação. Os dados provêm da PNAD, anos de 2006 e 2009, e as metodologias empregadas são a tradicional decomposição de Oaxaca-Blinder e uma alternativa não paramétrica proposta por Ñopo (2008), que decompõe em quatro termos o diferencial total, destacando o diferencial dentro de um suporte comum de características observáveis. Os resultados indicam que professores do Ensino Médio possuem diferencial de remuneração favorável, porém decrescente, quando comparados a funcionários públicos e empregados do setor privado. Além disso, e de modo mais preocupante, em comparação a profissionais com qualificação semelhante, a situação é desfavorável aos professores, e mostra deterioração de 2006 para 2009. Resultados obtidos utilizando ambas as metodologias indicam que este último diferencial em grande medida não é atribuível às diferenças nas distribuições de características individuais, mas muito mais à parcela não explicada, o que pode representar baixa valorização social de professores ou diferenciais de produtividade pré-escolha ocupacional ou pós-escolha ocupacional. Qualquer que seja a razão, o déficit de remuneração no mercado de trabalho docente pode ser um dos fatores explicativos do baixo interesse de jovens talentosos pelas licenciaturas com potenciais impactos negativos sobre a qualidade do aprendizado dos futuros alunos.

- Por importantes críticas, comentários e recomendações feitos a versões anteriores deste trabalho, os autores gostariam de agradecer a Marina Aguas, Fernando de Holanda Barbosa Filho, Luis Fernando Gamboa, Flávio Gonçalves, Celia Kerstenetzky, e participantes de seminários internos do NEE/CEDE/UFF e do $40^{\circ}$ Congresso da ANPEC, bem como pareceristas e editora deste periódico. A responsabilidade por esta versão final cabe exclusivamente aos autores. Ariana M. de Britto é grata à Faperj pelo apoio financeiro concedido via programa "Bolsa Nota 10 ", essencial à realização da pesquisa que resultou neste artigo. 


\title{
Palavras-Chave
}

diferenciais de salários, mercado de trabalho de professores, professores do Ensino Médio, atratividade da carreira docente, decomposição de Ñopo

\begin{abstract}
The article aims at evaluating the attractiveness of the teaching occupation at the secondary education level, as reflected by wage gaps between this category of teachers and other professional categories, based on PNAD data for 2006 and 2009. The methodologies employed in the paper include the traditional Oaxaca-Blinder's decomposition, as well as a non-parametric alternative proposed by Ñopo (2008), which decomposes a given gap in four terms, emphasizing the gap within a common support of observable characteristics. Main results indicate that secondary school teachers have a favorable, albeit decreasing, pay gap when compared to civil servants and private sector workers. Furthermore, and more disturbing, compared with similarly-skilled professionals, the situation becomes detrimental to teachers and it shows a decline from 2006 to 2009. Results obtained using both methodologies indicate that to a great extent the latter gap cannot be attributed to differences in the distributions of individuals' characteristics, but rather to the unexplained fraction, which could translate a low social valuation of the teachers' occupation, or a pre- or post-occupational choice productivity gap. In any case, the low pay for teachers might be one of the factors explaining the lack of interest of young talented individuals for pursuing careers in education and teaching.
\end{abstract}

\section{Keywords}

wage differentials, teachers' labor market, high school teachers, attractiveness of teacher's occupation, Nopo decomposition

\section{JEL Classification}

J31, J44, 121

\section{Introdução}

Do ponto de vista econômico, poucos bens ou serviços são tão intensivos em mão de obra quanto a educação. A proporção dos gastos com educação que são alocados para remuneração de professores em todos os níveis de ensino, à exceção do nível superior, corresponde em média a $92 \%$ dos gastos correntes na OCDE e mais de $70 \%$ no Brasil (OCDE, 2011). Como se trata de um setor com baixo potencial de ganhos de produtividade em comparação com outros setores, entre outras razões em função do baixo potencial de substituição entre capital e trabalho, é natural que se observe uma tendência de aumento gradual dos custos com pessoal (Baumol, 1993).

Do ponto de vista político, todas as discussões sobre reformas educacionais consideram, direta ou indiretamente, os professores como 
elemento essencial, não só pelas preocupações orçamentárias já apontadas, mas também porque o aprendizado de alunos depende em grande medida da qualidade dos professores. Envolvendo habilidades variadas, tais como talento (inato?), para lecionar, motivação e a capacidade de se adaptar a alunos de diferentes características, a qualidade do professor é uma variável intangível, de difícil definição e mensuração. Contudo, é plausível supor que a qualidade do professor guarde correlação positiva com o desempenho de alunos - hipótese defendida, por exemplo, por Erik Hanushek e seus coautores. ${ }^{1}$

Em relatório encomendado por empresa internacional de consultoria, com grande repercussão quando publicado, Barber e Mourshed (2007) estudaram os determinantes dos melhores sistemas educacionais, concluindo que "getting the right people to become teachers" teria sido fundamental para que alunos de países como Coreia e Finlândia alcançassem bom desempenho em exames padronizados internacionais. Estes países têm professores com as melhores remunerações ao longo de toda a carreira docente e em todos os níveis de ensino da educação básica. ${ }^{2}$ Possivelmente em consequência disso, professores são recrutados entre aqueles localizados no topo dos 5\% (Coreia) e 10\% (Finlândia) melhores alunos do ensino médio.

Diferentes aspectos podem influenciar a escolha da carreira docente versus outras ocupações, entre os quais: flexibilidade de horário, estabilidade no emprego, baixas exigências para exercício da docência, ou mesmo personalidade e características pessoais. ${ }^{3}$ Porém, a hipótese adotada em estudos que avaliam o impacto dos salários sobre a atração dos profissionais mais bem preparados considera que o diferencial de remuneração é fator preponderante quando um indivíduo considera docência versus outras carreiras (Podgursky, 2010). Salários mais altos tenderiam: (i) possivelmente, a aumentar a motivação dos professores no exercício de suas funções, (ii) provavelmente, a contribuir para reter (bons) docentes na profissão, e (iii) certamente, a atrair indivíduos bem preparados para a carreira. Sendo muito baixos os salários oferecidos aos professores, comparativamente ao que se paga em outras profissões, ceteris paribus, a qualidade dos novos entrantes seria menor que em outras ocupações e os docentes mais bem preparados estariam mais propensos a bus-

\footnotetext{
${ }^{1}$ Veja-se, por exemplo, Hanushek e Rivkin (2006).

2 Ver OCDE (2011, p.415).

3 Ver Harris e Sass (2009), Ham et al. (2009) e Humlum et al. (2012).
} 
car oportunidades em carreiras alternativas, ou a permanecer onde estão, porém desmotivados, visto o baixo prestígio da profissão.

No Brasil o gasto público com educação básica como percentual do PIB elevou-se de 2,6\% em 1995 para 4,1\% em 2008, ${ }^{4}$ entre outras razões como resultado de iniciativas como FUNDEF e FUNDEB. ${ }^{5}$ Anuatti-Neto et al. (2004) e Menezes-Filho e Pazello (2007) mostram que o FUNDEF teria sido eficaz em promover melhoria salarial entre os professores do ensino fundamental no setor público, principalmente para aqueles localizados nos estados e municípios mais carentes. Apesar das melhorias, na comparação salarial com os docentes de outros países, os brasileiros estão muito longe de países desenvolvidos. Um professor estatutário em início de carreira no Ensino Médio auferia anualmente, em 2009, cerca de US\$33 $\mathrm{mil}^{6} \mathrm{em}$ média nos países da OCDE, enquanto, no Brasil, o valor estava próximo de US $\$ 12$ mil. ${ }^{7}$ A Lei 11.738 , promulgada em 2008, que previa a regulamentação de um piso salarial nacional para os profissionais do magistério público da educação básica - recentemente alçado a $\mathrm{R} \$ 1.451,00$ - e melhores condições de trabalho ainda não foi adotada em todos os estados e municípios.

Como se sabe, no Brasil, duas tendências positivas têm sido observadas nos últimos anos: a de universalização do acesso ao Ensino Fundamental e a de melhoria do fluxo nesse nível de ensino, com redução da distorção idade-série. Tais tendências têm criado novas necessidades, entre as quais a de melhoria da qualidade nesse nível de ensino, além de maior demanda por profissionais para trabalhar no Ensino Médio. Com relação a este nível, menciona-se um potencial déficit de professores com formação adequada para certas áreas de atuação - às vezes denominado "escassez oculta" - sobretudo em matérias relacionadas às ciências exatas, em que não só a exigência

4 Ver OCDE (2011, p.229).

5 O FUNDEF (Fundo de Manutenção e Desenvolvimento do Ensino Fundamental e de Valorização do Magistério) foi implementado em 1998 e permaneceu até 2006, focando os primeiros anos da educação básica. Em 2007, foi substituído pelo FUNDEB (Fundo de Manutenção e Desenvolvimento da Educação Básica e de Valorização dos Profissionais da Educação) sendo, então, incluídos os profissionais de educação do Ensino Médio. O FUNDEB tornou-se também um instrumento de referência à definição do piso salarial nacional.

6 Ver OCDE (2011, p.415). Considera valores em dólares convertidos usando paridade do poder de compra (PPP).

7 Fonte: (PNAD, 2009). Refere-se ao valor do rendimento mensal médio no trabalho principal para os professores no Ensino Médio multiplicado por 13,33 (doze meses, mais décimo terceiro salário mais $1 / 3$ referente às férias) e convertido pela cotação do dólar comercial em 31.12.2009. Ver http://www.portalbrasil.net/2009/economia/dolar_riscopais_dezembro.htm 
de qualificação é maior, como também são maiores as oportunidades fora do setor educacional. Em 2010, segundo dados da Sinopse Estatística da Educação Básica, apenas 20\% dos professores com formação superior que atuavam no Ensino Médio tinham formação específica em áreas relacionadas a ciências, física ou matemática. Por fim, ressalte-se que o Ensino Médio torna-se um objeto de estudo ainda mais relevante tendo em vista a extensão recente do FUNDEF a FUNDEB.

O objetivo deste artigo é avaliar a atratividade da profissão de professor do Ensino Médio, tal como expressa pelos diferenciais salariais entre essa categoria e não professores de três grupos diferentes: (i) empregados nas demais ocupações do setor público, (ii) empregados nas demais ocupações do setor privado e (iii) profissionais das ciências e das artes (conceito explicado mais adiante). Para esses exercícios, utiliza-se como metodologia básica (benchmark) a técnica de decomposição de Oaxaca-Blinder (1973) dos resultados de equações de salários, estimados com dados da PNAD, de 2006 e 2009 - anos anterior e posterior à implantação do FUNDEB. Além disso, recorre-se também a uma técnica de decomposição mais sofisticada, não paramétrica, introduzida por Ñopo (2008), que permite decompor a diferença salarial entre dois grupos de indivíduos em quatro componentes, ao invés de apenas dois, e que pode ser considerada o estadoda-arte no que se refere a decomposições de diferenciais salariais. Essa decomposição quadripartite permite identificar exatamente a parcela do diferencial salarial que se encontra no suporte comum das distribuições de características dos dois grupos, evitando que se façam comparações indevidas entre indivíduos de características distintas.

O artigo está estruturado em cinco seções, incluindo esta introdução. Na segunda seção, há considerações teóricas e análises de evidências empíricas internacionais e nacionais sobre dois temas: (a) a relação entre remuneração de professores e escolha ocupacional, e (b) diferenciais salariais entre professores e demais ocupações. Na terceira seção, são descritas as metodologias e os dados empregados, sucedida pela quarta seção, na qual são apresentados e discutidos os principais resultados. A última seção contém conclusões. 


\section{Remuneração de Professores: Considerações Teóricas e Evi- dências Empíricas}

\subsection{Remuneração de Professores e Escolha Ocupacional}

Tradicionalmente, via-se a docência do ponto de vista vocacional, como uma carreira escolhida por quem, tendo o "dom de ensinar", buscava uma realização pessoal. A teoria econômica que avalia as preferências dos agentes sob a perspectiva da escolha ocupacional docente leva em conta, na função de utilidade do professor, a combinação de fatores pecuniários e não pecuniários, entre os quais se incluem: salários, características pessoais e domiciliares, contexto social e condições do trabalho. Hernani-Limarino (2005) argumenta que considerar salários como o único determinante do custo de oportunidade levado em conta pelos indivíduos na escolha da carreira docente seria uma hipótese muito restritiva, uma vez que fatores não monetários como estabilidade, número de horas trabalhadas, flexibilidade na profissão, além de benefícios como férias mais longas, seriam ao menos tão relevantes. Além disso, o autor sugere que a preferência dos que optam pela carreira de professor poderia refletir um perfil específico de indivíduos, com características como forte aversão ao risco, de forma que estariam dispostos a trocar salários mais altos de outras ocupações pela relativa estabilidade da profissão docente.

Contribuições recentes têm buscado avaliar aspectos associados a traços da personalidade, maturidade, interesses e habilidades na escolha dos jovens. E as evidências sugerem que, de fato, características individuais representariam um determinante importante na escolha ocupacional. Ham et al. (2009), com dados australianos, avaliam o impacto sobre a escolha ocupacional de fatores relacionados à personalidade, encontrando efeito positivo e significativo. ${ }^{8}$

Humlum et al. (2012) destacam a relevância do status social para a escolha ocupacional na Dinamarca. A partir da construção de indicadores de características de personalidade nas distintas carreiras, e com base no modelo de Akerlof e Kranton (2000), os autores analisam os efeitos de fatores ligados à identidade individual na análise

8 O estudo restringe-se a trabalhadores de atividades manuais (white collar), em oposição às profissões blue collar. No primeiro grupo encontram-se: ocupações administrativas em geral, advogados, administradores, secretárias etc. Em contrapartida, as ocupações blue collar são representadas por: mecânicos, eletricistas, pintores, cozinheiros, encanadores etc. 
da escolha ocupacional de estudantes do Ensino Médio. O estudo sugere que alunos que obtiveram notas maiores em características ligadas a "fatores sociais" ${ }^{9}$ teriam maior propensão a optar por carreiras cujo enfoque estivesse diretamente relacionado a trabalhar com pessoas, como a educação. Adicionalmente, apoiados por um modelo logit, os autores mostram que o aumento de uma unidade no desvio-padrão do "fator social" aumentaria a utilidade esperada de escolher carreiras ligadas à educação e humanidades em relação a outras carreiras numa intensidade equivalente a um aumento salarial anual de US\$3.749.

No Brasil, a indisponibilidade de dados sobre motivações e interesses dos alunos ao final do Ensino Médio dificulta a análise da escolha ocupacional docente. Dados do questionário socioeconômico do Exame Nacional de Desempenho dos Estudantes (ENADE) aplicados aos cursos de pedagogia e licenciaturas em 2005 mostram que, além das dificuldades econômicas $(80 \%$ dos alunos cursaram o Ensino Médio em escolas públicas, 39\% tinham renda familiar inferior a 3 salários mínimos e cerca de $3 / 4$ dos alunos já exerciam alguma atividade remunerada), os ingressantes desses cursos chegam ao ensino superior com bagagem cultural limitada (45\% declaram conhecimento praticamente nulo de inglês). ${ }^{10}$

Dados mais recentes, referentes a 2008, mostram que esse perfil vem se consolidando entre os alunos que optam pela carreira docente (Gráfico 1). As dificuldades econômicas reforçam um perfil preocupante de nossos futuros professores, uma vez que $64 \%$ dos alunos provêm de famílias com renda familiar mensal inferior a três salários mínimos, proporção que representa um crescimento de $25 \%$ em apenas três anos. A maior parte dos ingressantes cursara o Ensino Médio em escola pública (78\%) e trabalhava (78\%), não só para pagar os estudos (68\% não recebia qualquer auxílio para sua formação), mas também para contribuir com o sustento da família (35\%).

\footnotetext{
9 "O "fator social" considera variáveis que refletem atitudes cooperativas e sociais na educação e na vida em geral, isto é, questões que refletem a importância de ajudar as pessoas e responsabilidade social e, portanto, estariam relacionados à identidade social de um indivíduo na vida profissional". Para identificar esses fatores, os autores consideraram parte da avaliação do PISA 2000, composta de um registro socioeconômico detalhado dos alunos, além de questões sobre escolha da carreira, que incluem perguntas sobre atitudes dos alunos em relação à educação, vida profissional e social.

${ }^{10}$ Ver Ratier (2010, p.13).
} 


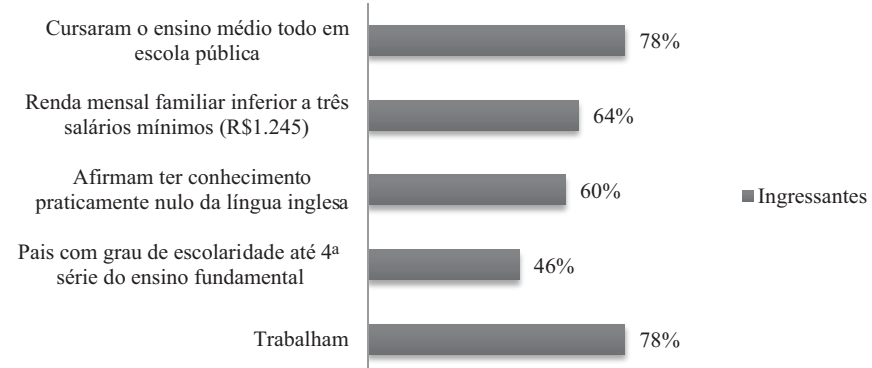

Gráfico 1 - Perfil dos alunos ingressantes dos cursos de pedagogia e licenciaturas (2008)

Elaboração própria.

Fonte: Questionário socioeconômico ENADE (2008).

Os resultados do ENADE revelam um aspecto positivo, contudo: seguir a carreira do magistério é uma opção bem definida pelos alunos ingressantes ( $74 \%$ deles declaram que querem ser professores, o que era de se esperar), sofrendo pouca influência ao longo do curso, conforme se pode verificar nos resultados das estatísticas dos alunos concluintes $(76 \%$ deles confirmaram que pretendem atuar na docência). Entre os motivos que mais influenciam estes jovens a escolher diferentes licenciaturas estão (Gráfico 2): a identificação com a carreira (62\% dos ingressantes e $64 \%$ dos concluintes) e a possibilidade de ter uma segunda carreira $(11 \%$ e $10 \%$, respectivamente ingressantes e concluintes). ${ }^{11}$

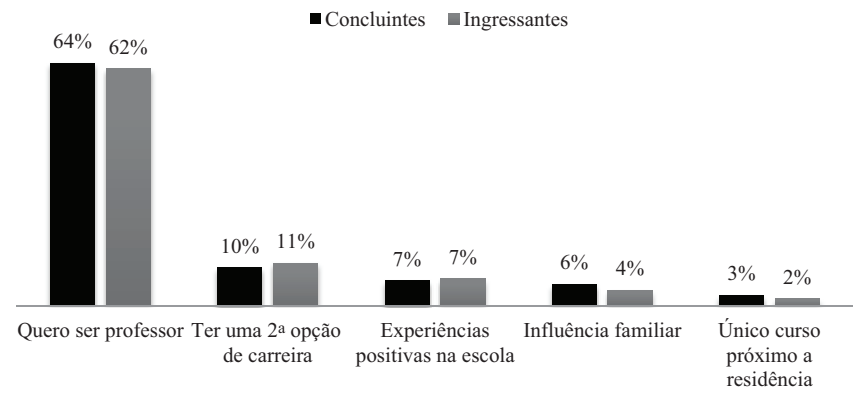

Gráfico 2- Razões que levaram à escolha da carreira de licenciatura dos alunos ingressantes e concluintes no curso de pedagogia no Brasil (2008)

Elaboração própria.

Fonte: Questionário socioeconômico ENADE (2008).

${ }^{11}$ Não há, entre as alternativas de resposta, motivos relacionados a retornos financeiros da carreira. 
Um levantamento recente foi produzido pela Fundação Carlos Chagas (2009), com base em pesquisa qualitativa que envolveu entrevistas com 1.501 alunos de escolas públicas e privadas no último ano do Ensino Médio. Dentre as principais razões citadas por jovens ao final do Ensino Médio para se tornarem professor encontramse: o histórico positivo de experiências educacionais, a possibilidade de auxiliar no aprendizado de pessoas mais jovens e a de trabalhar com crianças. Entre as causas que obstruem a opção pelo magistério, registram-se: a falta de identificação profissional ou pessoal com a carreira, além da baixa remuneração. Também são muito citados fatores como: condições de trabalho (destacando-se a percepção de aumento da violência nas escolas) e o baixo prestígio social da carreira. Segundo esse levantamento "o declínio do prestígio da ocupação docente teria relação direta com a decadência dos salários". ${ }^{2}$

Em suma, fatores sociais e características pessoais - incluindo vocação - têm sua importância como elementos de atratividade da carreira docente, contudo não parece plausível supor que tais fatores, por si só, sejam suficientes para atrair indivíduos bem preparados e motivados. Nessa linha, diversos autores têm buscado avaliar a atratividade da carreira docente a partir do impacto dos salários dos professores comparativamente a outros profissionais com características similares.

\subsection{Diferenciais Salariais entre Professores e Não Professores: Evidências Internacionais}

Distintos estudos têm analisado o papel da remuneração dos professores na motivação, atração e permanência na carreira docente. Especialmente na América Latina, esse assunto tem sido recorrente na literatura, seja em análises comparativas internacionais, seja em análises específicas nacionais. Num dos primeiros estudos sobre diferenciais salariais comparando (doze) países da América Latina, elaborado por Psacharopoulos et al. (1996), apresenta-se um paralelo entre as remunerações médias de professores e profissionais de demais ocupações, utilizando-se equações mincerianas, mas não se identifica um padrão que valha para todos os países. A fim de obter resultados mais apurados, Liang (1999), incorpora controles sobre a

12 Ver pesquisa "Atratividade da carreira docente no Brasil" (FCC/FVC, 2009, p.14). 
escolaridade (restringindo o grupo de comparação a indivíduos com ao menos seis anos de escolaridade) e sobre a variável dependente (rendimentos ajustados para horas trabalhadas, além da inclusão de valoração para os respectivos períodos de férias, maiores para professores). Quando a variável dependente é representada pelo rendimento-hora, as diferenças de remuneração entre professores e não professores seriam "quase nulas" em quase todos os países, à exceção de Brasil e Equador, onde professores estariam em desvantagem.

Hernani-Limarino (2005) analisa a robustez dos resultados de diferenciais de salários em dezessete países latino-americanos, considerando grupos de comparação distintos em um único momento do tempo. Utilizando a metodologia de Oaxaca-Blinder (1973), o autor mostra que tanto o sinal quanto a magnitude do diferencial são bastante sensíveis à definição dos grupos de comparação. Quando os professores são comparados com trabalhadores de ocupações técnicas, não controlando para o nível de escolaridade, os resultados são favoráveis aos professores em quatorze dos dezessete países analisados, sendo o Brasil novamente uma das exceções. A maior parte da vantagem nos demais países é atribuída ao fato de que, na média, os professores têm nível de escolaridade superior aos demais trabalhadores. O autor também compara os diferenciais de salários em diferentes quantis da distribuição condicional dos salários e conclui que as diferenças tendem a ser positivas e maiores em favor de professores, sobretudo quando estes se encontram na base da distribuição. ${ }^{13}$

Entre esses estudos que comparam países da América Latina, o mais recente é o de Mizala e Ñopo (2011), em que se conclui que os professores são, na média, mal remunerados na América Latina. Os autores também ressaltam a importância da sensibilidade dos resultados à definição do grupo de comparação e obtêm novas evidências sobre o impacto do componente de heterogeneidade não observada, em concordância com os resultados de Hernani-Limarino (2005). Os professores são comparados a profissionais (com ao menos Ensino Médio completo) em nove países e os principais resultados levam a crer que os professores - especialmente aqueles que atuam no nível pré-escolar e fundamental - apresentam menor retorno que o grupo de comparação.

${ }^{13} \mathrm{O}$ autor interpreta a posição na distribuição condicional do log dos salários como uma medida da habilidade não observada (Hernani-Limarino, 2005:94). 
O diferencial de remuneração é mais desfavorável para: professores homens, mais velhos, com ensino superior completo, que vivem em áreas urbanas e têm empregos formais.

Outros estudos limitam-se a analisar países específicos. Chanduvi (2004) utiliza equações mincerianas para estimar o diferencial de rendimentos entre professores e não professores no Peru e conclui que, em geral, os docentes naquele país auferem $7 \%$ mais que indivíduos com características e empregos similares. Os hiatos de ganho entre professores e demais comparações são sensíveis à localização geográfica (docentes ganham menos em Lima) e ao gênero (prêmio de $4 \%$ para professores homens). Para o México, analisando o retorno do "contrato de trabalho ao longo da vida", ${ }^{14}$ Lopez-Acevedo (2004) encontra que professores de escolas públicas mexicanas, apesar de apresentarem retorno médio à escolaridade menor em comparação aos professores da rede privada e demais grupos de trabalhadores, recebem salários iniciais mais altos e melhores benefícios de aposentadoria.

Mizala e Romaguera (2005) para o Chile, e Piras e Savedoff (1998) para a Bolívia, valeram-se do tradicional método de decomposição de Oaxaca-Blinder (1973). Na Bolívia, os docentes de escolas públicas sindicalizados recebem $10 \%$ mais que o restante do funcionalismo público. No Chile, somente características observáveis são consideradas e, na média, os ganhos de professores são similares aos que receberiam em outras ocupações, representadas por todos os demais trabalhadores, à exceção de trabalhadores agrícolas, com mais de 15 anos.

Em países em desenvolvimento não latino-americanos, os salários costumam ser mais claramente favoráveis aos grupos de comparação. Gustafsson e Patel (2008) argumentam que, na África do Sul, apesar de sucessivos aumentos com o objetivo de equiparar salários entre profissionais da educação e trabalhadores com mesmo nível de formação, os professores ainda recebem quase duas vezes menos que não professores, mesmo levando em conta características observáveis. Contudo, a variável dependente não é ajustada para as horas trabalhadas, o que pode subestimar o total de rendimentos dos professores.

\footnotetext{
${ }^{14}$ Isto é, o valor presente do fluxo de rendimentos da carreira e da aposentadoria, detalhado mais adiante neste artigo.
} 
Asadullah (2006) também recorre ao método de Oaxaca-Blinder para avaliar a situação em Bangladesh e verifica que os professores recebem salários significativamente menores comparativamente aos não professores (trabalhadores com ao menos 10 anos educação e com idade acima de 18 anos) que possuem características similares, diferencial explicado principalmente pelo retorno às características observáveis.

Em resumo, as evidências empíricas internacionais são divergentes, ora favorecendo os professores, ora favorecendo os grupos de comparação, não sendo possível definir um padrão claro sobre se os professores efetivamente recebem salários menores que os grupos de comparação. Contudo, é possível afirmar que este diferencial, considerando sua magnitude e sinal, está fortemente relacionado à definição dos grupos de comparação, o que evidencia o cuidado que deve ser tomado em sua escolha.

\subsection{Diferenciais Salariais entre Professores e Não Professores: Evidências Nacionais}

Grande parte dos estudos nacionais estima diferenciais salariais entre setores de atuação (público vs. privado), controlando-se para características observáveis, a partir de diferentes metodologias, a exemplo de Barros et al. (2001), Anuatti-Neto et al. (2004) e Moriconi (2008). Além da preocupação advinda da definição dos grupos de comparação, já mencionada anteriormente, outra questão metodológica recorrente diz respeito ao conceito de salário a ser privilegiado. Os modelos tradicionais consideram a remuneração média mensal recebida pelos indivíduos, que compreende somente os salários, desconsiderando-se outras fontes de renda (como juros, aluguéis, pensões etc.) e vantagens não pecuniárias (férias). Autores como Becker (2008) e Barbosa-Filho et al., (2009) não usam salários mensais, mas sim "contratos de trabalho", isto é, o valor presente do fluxo de renda recebido ao longo de toda a vida por professores e grupos de comparação.

Num dos estudos pioneiros a tratar do mercado de trabalho de professores no Brasil, Barros et al. (2001) avaliam a atratividade da carreira docente a partir da hipótese de que a escolha da carreira está condicionada a características do posto de trabalho e do próprio 
trabalhador, ${ }^{15}$ em relação a três grupos de comparação: professores no ensino privado e demais trabalhadores (setores público e privado). No primeiro caso, os autores definem como padrão de comparação uma mulher, branca, com 30 anos de idade, 11 anos de estudo e residente no interior da região Sudeste, e concluem que, apesar de não identificarem diferenças relevantes entre as regiões do país, os professores (em especial, de escolas estaduais) apresentam vantagem remunerativa. No segundo caso, os autores consideram o diferencial médio da remuneração para todos os trabalhadores, utilizando uma equação linear dos salários e os resultados mostram que, em média, os professores receberiam salários maiores se atuassem no setor privado ou em outra atividade no setor público.

Anuatti-Neto et al. (2004) partem dos mesmos grupos de comparação utilizados em Barros et al., (2001) a fim de avaliar se professores públicos eram mal remunerados no final do século passado, apesar de políticas então adotadas pelo governo para valorização do professor, especificamente o FUNDEF. Os resultados sugerem que a implantação desse mecanismo de financiamento trouxe impactos positivos para os salários dos professores, em especial para os menores municípios e para profissionais da rede municipal e localizados na região Nordeste. Contudo, também é possível observar que, para o ano 1999, professores da rede pública, em média, ainda auferiam rendimentos menores comparativamente aos grupos de comparação, à exceção dos demais empregados do setor privado.

Mais recentemente, Moriconi (2008) avalia a atratividade da carreira docente no setor público, expressa pelo diferencial de rendimentos entre professores e demais categorias ocupacionais (empregados do setor privado, inclusive professores, e funcionários públicos). Ao contrário de outros estudos que avaliam um único ponto no tempo, a autora analisa a evolução temporal dos diferenciais de rendimento com base nas PNADs de 1995 a 2006. São efetuadas análises segmentadas por escolaridade (média e superior), regiões do Brasil e gênero. Um resultado importante mostra o declínio do diferencial de remuneração entre professores e grupos de comparação, especialmente no setor privado e nas regiões Sudeste e Centro-Oeste.

\footnotetext{
${ }^{15}$ Os diferenciais de qualidade do posto de trabalho levaram em conta as seguintes categorias para os grupos de comparação: Professores do Ensino Fundamental Privado (Com e Sem Carteira); Professores do Ensino Fundamental Público (Estadual e Municipal e subcategorias em ambos - Estatutário e Não Estatutário); Empregados do Setor Privado (Com e Sem Carteira) e Funcionários Públicos (Executivo, Legislativo e Judiciário).
} 
A autora reforça a noção geral de que os professores são mal remunerados, em especial quando se avaliam os profissionais com alto nível de escolaridade. Os resultados indicam que os professores com nível superior chegam a receber $50 \%$ menos que profissionais que atuam no funcionalismo público e $19 \%$ menos que professores que atuam no setor privado.

Alguns estudos recentes optaram por levar em conta os rendimentos de aposentadoria. Barbosa-Filho et al. (2009) consideram o que denominam "valor presente do contrato de trabalho" (ou VPCT), ${ }^{16}$ calculado com base na remuneração potencialmente recebida ao longo de toda a vida para professores das redes pública e privada. Usando dados dos censos demográficos de 1980, 1991 e 2000, concluem que o VPCT é sempre mais elevado no ensino público que no setor privado.

Becker (2008) utiliza a técnica de Oaxaca-Blinder (1973) para, também com base no VPCT, comparar os diferenciais de remuneração entre professores do ensino fundamental e três grupos ocupacionais: professores da rede privada, profissionais com alta e média qualificação (profissionais de ciências e do setor de produção e serviços, respectivamente).

Os resultados apontam que, ao não considerar os rendimentos auferidos pelos indivíduos ao longo de toda a vida, o diferencial sobre-estimaria a desvantagem dos professores em relação às demais carreiras. A autora mostra haver redução significativa no déficit de remuneração médio de professores no ensino fundamental com relação a profissionais da ciência (de $178 \%$ para $76 \%$ ), ao se considerar o perfil de rendimentos ao longo do ciclo de vida dos trabalhadores, mas não uma eliminação de tal déficit. ${ }^{17}$ Ao realizarem sua escolha ocupacional, num quadro intertemporal, professores optariam por

${ }^{16}$ O VPCT é uma medida de renda ao longo da vida e incorpora, além do salário bruto, a contribuição e os benefícios da aposentadoria. Os parâmetros de cálculo da contribuição previdenciária são: a renda do trabalhador, as alíquotas de contribuição do empregador e o teto de contribuição (quando existir). Já para os benefícios previdenciários são considerados: a idade da aposentadoria, a regra de cálculo do valor da aposentadoria, forma de reajuste do valor real da aposentadoria, e alíquotas de contribuição do trabalhador inativo (se existir). Os cálculos são aplicados a cada subgrupo: professores das redes: pública e privada, em todos os níveis de ensino. Por fim, os cálculos são efetuados considerando taxas de desconto entre $3 \%$ a $7 \%$ ao ano, escolha feita com base na taxa de juros real brasileira - em torno de $5 \%$ ao ano - nos últimos 40 anos.

17 A autora considera uma taxa de desconto de $5 \%$, pressupõe estado estacionário, utilizando regras previdenciárias de 2006 e idade de início de contribuição de 21 anos. 
sua carreira abrindo mão da possibilidade de rendimentos imediatos mais elevados, em troca de benefícios na aposentadoria, o que ecoaria certa aversão ao risco por parte de professores, sugerida na literatura (Liang, 1999).

\section{Metodologia e Dados}

\subsection{Metodologias de Decomposição de Oaxaca-Blinder e de Ñopo}

A decomposição utilizada inicialmente baseia-se na técnica de Oaxaca-Blinder (Oaxaca, 1973; Blinder, 1973), frequente na literatura de diferenciais salariais por gênero e raça, a qual, após a estimação preliminar de equações de salário para o grupo de referência e para grupos de comparação, permite que se decomponha o diferencial de rendimentos entre a contribuição das características observáveis ("parte explicada") e das não-observáveis ("parte não-explicada"). Na decomposição, portanto, as regressões de salários são estimadas separadamente para cada grupo - professores ${ }^{18}(\mathrm{P})$ e não-professores (NP), em nosso caso -, permitindo que o grupo de referência e os de comparação enfrentem estruturas diferentes de valorização de retornos às características. Esta é a principal vantagem desta metodologia, comparativamente ao método de Mincer (1974), cujo diferencial salarial é obtido a partir do uso de uma variável dummy para cada grupo em uma regressão única de salários, controlando para características observáveis dos trabalhadores que afetam seus rendimentos como escolaridade, gênero, experiência, etc.

Depois de estimadas as equações de salários para cada grupo, $\bar{w}_{P}=\hat{\beta}_{P} \bar{X}_{P}$ para professores, e $\bar{w}_{N P}=\hat{\beta}_{N P} \bar{X}_{N P}$ para não professores, a decomposição de Oaxaca-Blinder corresponde à equação (1):

$$
\bar{w}_{N P}-\bar{w}_{P}=\left(\bar{X}_{N P}-\bar{X}_{P}\right) \hat{\beta}_{N P}+\left(\hat{\beta}_{N P}-\hat{\beta}_{P}\right) \bar{X}_{P}
$$

Onde $\bar{w}_{g}$ representa o logaritmo do salário horário do grupo $g=P, N P$, enquanto $\hat{\beta}_{g}$ corresponde a vetores de coeficientes estimados associados a professores e não professores, $\bar{X}_{g}$ são vetores de características pessoais, laborais e geográficas de professores e não professores. 
O primeiro termo do lado direito da decomposição, $\left(\bar{X}_{N P}-\bar{X}_{P}\right) \hat{\beta}_{N P}$, representa o componente "explicado", também chamado de "efeito dotação", o qual mede o diferencial de ganhos estimado em virtude de diferenças nas características observáveis entre professores e não professores, tais como, idade, experiência, anos de estudo e local de moradia. O segundo termo do lado direito da equação, $\left(\hat{\beta}_{N P}-\hat{\beta}_{P}\right) \bar{X}_{P}$, representa o componente "não explicado" e mede as diferenças nos rendimentos em virtude das diferenças na estrutura de retornos das características. ${ }^{19}$

A estrutura de retornos considerada como referência pode ser a do grupo de não professores, a de professores ou ainda uma combinação entre elas. Com relação a esta última possibilidade, diversos autores têm proposto modelos que se pretendem mais gerais, a fim de considerar uma combinação entre as duas estruturas, atribuindo um peso não arbitrário a cada um dos grupos (ver Cotton, 1988; Oaxaca e Ransom, 1994; Kunze, 2000). Contudo, tais autores argumentam que a definição do peso não é simples e muito do que há ainda é arbitrário. A opção mantida neste estudo foi definir a estrutura de não professores como a estrutura padrão com a qual os professores serão comparados. A justificativa para utilizar os parâmetros da regressão amostral dos não professores foi extraída da literatura de diferenciais por gênero, na qual se privilegia o grupo majoritário. ${ }^{20}$

Em evolução recente da literatura, Nopo (2008) argumenta que a decomposição de Oaxaca-Blinder superestimaria o componente do diferencial atribuído às diferenças não observáveis, uma vez que poderia haver combinações de características individuais que existem num grupo, mas inexistem em outro. A proposta para resolução desse problema leva em conta as diferenças nas distribuições das características dos indivíduos por meio da utilização de um mode-

${ }^{18}$ A partir desta seção, sempre que se estiver referindo somente a professores, tratar-se-á de professores do Ensino Médio.

${ }^{19}$ Em reação a algumas críticas, a decomposição de Oaxaca-Blinder foi estendida, incorporando um terceiro termo que representa a interação entre os coeficientes e as dotações, representando o fato de que as diferenças nas dotações e nos coeficientes existiriam simultaneamente entre os grupos (Jann, 2008). Para não alongar demais o artigo, não se apresentam aqui os resultados da decomposição estendida, chamada three-fold decomposition, contudo, os resultados podem ser solicitados diretamente aos autores.

${ }^{20}$ Kunze (2000, p. 40), em extensa pesquisa realizada sobre o tema, argumenta que a abordagem usual da decomposição de Oaxaca-Blinder utiliza os coeficientes de regressão ponderados para homens para medir o efeito discriminatório dos salários. Ainda, segundo o autor, "a justificativa para utilizar os parâmetros da regressão amostral dos homens como o vetor dos preços competitivos é que se pode assumir que na economia, os trabalhadores homens são o maior grupo e enfrentam, virtualmente, nenhuma discriminação." 
lo não paramétrico através de um procedimento de pareamento. Nessa abordagem, a comparação relevante restringe-se àquela feita entre indivíduos que se encontrem dentro de um suporte comum de características.

Na metodologia de Nopo parte-se do diferencial calculado a partir do valor esperado dos ganhos condicional às características observáveis (relacionadas a esses ganhos) e da função de distribuição acumulada das características observáveis, dado que o indivíduo não é professor e dado que o indivíduo é professor:

$$
\Delta \equiv E[w \mid N P]-E[w \mid P]
$$

É possível - provável, em certos casos - que o suporte da distribuição de características do grupo de não professores seja diferente do suporte da distribuição de características dos grupos de professores. Nesse sentido, seria aceitável subdividir cada termo do lado direito da equação acima em dois termos, um dentro da interseção de suportes (ou "suporte comum") e outro específico ao grupo em questão (fora do "suporte comum"). Por fim, o termo que corresponde ao suporte comum pode ser decomposto da mesma forma como se faz na decomposição de Oaxaca-Blinder, obtendo-se assim dois termos com a mesma interpretação tradicional, porém, definidos somente no domínio do suporte comum. Em suma, o diferencial agora é decomposto levando em conta as diferenças nos salários esperados de professores e não professores dentro e fora do suporte comum: ${ }^{21}$

$$
\Delta=\Delta_{N P}+\Delta_{P}+\Delta_{X}+\Delta_{O}
$$

O componente $\Delta_{N P}$ captura a fração do diferencial que é explicada pelas diferenças entre dois grupos de não professores, um com características que podem ser pareadas com as características dos professores e outro que não pode. Este seria zero se não houvesse não professores não pareados com professores - em outras palavras, se professores e não professores fossem grupos bem parecidos - ou se os não professores não pareados recebessem remuneração semelhante

\footnotetext{
21 "A metodologia de Ñopo (2008) é construída a partir do diferencial salarial entre homens e mulheres. A nomenclatura utilizada pelo autor foi adaptada para os grupos de comparação utilizados neste artigo, ou seja, onde lê-se na versão original Male, estes correspondem ao grupo majoritário (aqui, não-professores); da mesma forma, Female correspondem ao grupo de professores.
} 
à dos professores pareados. O segundo componente, $\Delta_{P}$, é análogo ao primeiro, porém, para professores. O terceiro componente, $\Delta_{X}$, captura o diferencial explicado por características entre professores e não professores que estão no suporte comum, com interpretação equivalente ao termo $\left(\bar{X}_{N P}-\bar{X}_{P}\right) \hat{\beta}_{N P}$ da decomposição de OaxacaBlinder. Por fim, $\Delta_{0}$, representa a parte não explicada do diferencial, equivalente ao componente não explicado da decomposição de Oaxaca-Blinder, $\left(\hat{\beta}_{N P}-\hat{\beta}_{P}\right) \bar{X}_{P}$. Os dois primeiros termos, por assim dizer, "limpam" os componentes de interesse principal, que são os dois últimos.

Ñopo (2008) destaca ainda que os três primeiros termos referemse a prêmios salariais em função de características observáveis, enquanto o quarto termo captura uma combinação entre diferenças não observáveis premiadas pelo mercado de trabalho e, eventualmente, discriminação (no contexto de diferenciais raciais ou por gênero) ou escolha (em nosso contexto). Com esta apresentação, representada pela Equação 4, fica ainda mais clara a analogia com a decomposição de Oaxaca-Blinder.

$$
\Delta=\left(\Delta_{N P}+\Delta_{P}+\Delta_{X}\right)+\Delta_{O}
$$

A estimação dos quatro componentes é realizada através de um procedimento recursivo de pareamento apresentado pelo autor nas seguintes etapas: ${ }^{22}$

1. Um professor é selecionado da amostra, sem reposição;

2. São selecionados todos os não professores com características observáveis semelhantes às do professor selecionado na etapa 1 ;

3. Tomam-se os não professores selecionados e constrói-se um "indivíduo sintético", cujas características sejam iguais à média de todos aqueles selecionados na etapa 2, e pareia-se este indivíduo sintético ao professor da etapa l;

22 Para maiores detalhes, ver Ñopo (2008, p.6-11). 
4. O professor selecionado na etapa 1 e o indivíduo sintético criado na etapa 2 são colocados na nova amostra de indivíduos pareados;

5. Repete-se o procedimento para cada professor.

A nova amostra gerada conterá, portanto, quatro tipos de indivíduos: não professores pareados, professores pareados, não professores não pareados e professores não pareados, e servirá ao propósito da decomposição quadripartite do diferencial. O número de características empregadas no modelo para determinar o pareamento determina o tamanho dos subconjuntos. O procedimento adotado pelo autor é adicionar variáveis uma-a-uma até obter o conjunto completo que inclui todas as características observáveis utilizadas no modelo e reportar tanto os resultados intermediários como os finais. Neste estudo, fazemos o mesmo, embora a apresentação de resultados se foque essencialmente no conjunto completo de características.

Presume-se que indivíduos com características iguais deveriam $a$ priori ser remunerados igualmente no mercado de trabalho, independentemente de gênero ou raça, temas abordado por Ñopo (2008) em seu artigo, ou da área de atuação (professores versus não professores), como em nosso trabalho - isto é, $\Delta_{0}$ deveria ser zero. Quando isto não for verificado, restará dúvida sobre as razões para tal resultado. Descartando-se a hipótese de discriminação contra professores (ou não professores), não será possível afirmar se este componente do diferencial de remuneração se deve a certa desvalorização social da ocupação docente (ou de não professores), ou à existência de características não observáveis ao econometrista, que explicariam tanto a escolha ocupacional docente, como também uma remuneração menor no mercado de trabalho. Assim, optou-se pela inclusão de covariadas que traduzissem características que poderiam influenciar a alocação dos trabalhadores entre a carreira docente versus demais ocupações. Tais variáveis serão detalhadas na próxima seção.

Com a técnica de Ñopo (2008), não é recomendável o uso de variáveis contínuas, pois isto aumentaria muito a probabilidade de não pareamento. Por essa razão, as variáveis contínuas devem ser transformadas em variáveis categóricas ou, quando possível, em binárias. Assim, além da inclusão de novas variáveis, a transformação de variáveis contínuas em categóricas ou binárias constitui outra diferença entre as equações de salários estimadas para uso com a metodologia 
de Oaxaca-Blinder as características usadas para pareamento com a técnica Nopo (2008). ${ }^{23}$

\subsection{Amostra, Variáveis Selecionadas e Grupos de Comparação}

Os dados utilizados provêm da Pesquisa Nacional por Amostra de Domicílios (PNAD) de 2006 e 2009, um ano antes e dois anos depois, respectivamente, do início da implantação do FUNDEB. Em 2006 foram entrevistadas 410.241 pessoas em 145.547 domicílios, com uma leve redução no tamanho da amostra de pessoas para o ano de 2009 quando foram entrevistadas 399.387 pessoas em 153.837 domicílios. Algumas restrições à amostra original foram efetuadas.

Primeiramente, foi mantida somente a área urbana, de um lado, pelas próprias particularidades das escolas localizadas na área rural e, de outro lado, porque a proporção de docentes na área rural é muito pequena em ambos os períodos analisados - 3\% e 4\%, em 2006 e 2009, respectivamente (Censo Escolar, 2006 e 2009). Com relação à idade, restringiu-se a amostra às pessoas que possuíam trabalho remunerado, na faixa etária entre 25 anos (quando se entende que os indivíduos já teriam tomado suas decisões iniciais sobre estudos e trabalho) e 55 anos (quando os indivíduos já estariam aposentados ou se aproximando da aposentadoria).

Adicionalmente, foram excluídos também os trabalhadores conta própria, trabalhadores domésticos com e sem carteira assinada, e os empregadores, por ser ínfimo o número de professores do Ensino Médio com tais características e porque, dadas as especificidades dessas categorias ocupacionais, são usualmente excluídas nos estudos sobre diferenciais salariais. Assim, na amostra final permaneceram 66.584 indivíduos em 2006 e 71.286 em 2009.

Foram consideradas variáveis explicativas tradicionalmente utilizadas na literatura: 24 idade, idade ao quadrado, experiência nesse trabalho, experiência nesse trabalho ao quadrado, anos de estudo, dummies para cor, gênero, grandes regiões brasileiras e filiação sindical.

23 Já foi desenvolvido comando para uso com o software econométrico Stata que efetua a decomposição de Ñopo (2008). Trata-se do comando nopomatch, o qual foi utilizado na elaboração deste trabalho.

${ }^{24}$ Alguns estudos que utilizam parcial ou totalmente as variáveis aqui apresentadas são: Hernani-Limarino (2005), Gilpin (2011), Mizala e Ñopo (2011), Moriconi (2008), Becker (2008). 
Em termos de medida de remuneração, a PNAD fornece informações sobre o rendimento de todos os trabalhos (principal, secundário, etc.) para pessoas com 10 anos ou mais de idade, além do número de horas trabalhadas em cada ocupação. A variável dependente que definimos corresponde ao logaritmo do rendimento-hora no trabalho principal, ${ }^{25}$ representado pela remuneração mensal bruta medida em reais, dividida pelo número total de horas trabalhadas no mês. Esta variável não inclui os recebimentos de $13^{\circ}$ salário, de participação nos lucros pagos pelos empregadores e benefícios como vale-alimentação, vale-transporte, etc. A escolha da variável salário horário justifica-se pelo fato de, em geral, os professores trabalharem menos horas que os profissionais das demais ocupações. Todas as variáveis monetárias são expressas em reais de 2009.

A opção pelo uso de uma taxa de desconto exponencial nos estudos com VPCT é controvertida, uma vez que evidências mostram que o desconto hiperbólico - intertemporalmente inconsistente - é mais usual (Bowles, 2004; Gintis, 2011). Descontando hiperbolicamente, o efeito das vantagens em termos de aposentadoria de determinada ocupação com relação a outras seria muito forte pouco antes da aposentadoria, ao passo que, no curto prazo, a tendência seria de valorizar, sobretudo as alternativas salariais correntes. Além disso, estamos vivendo um período de transição em termos de regras de aposentadoria de funcionários públicos, em função da recente aprovação do estabelecimento do Fundo de Previdência Complementar do Serviço Público Federal (FUNPRESP), que equipara o teto de benefícios de aposentadoria dos novos servidores públicos ao dos empregados do setor privado, de forma que a vantagem intertemporal de professores (e demais servidores) do sistema público, identificada nos estudos que usam VPCT, deixará de existir em breve. Logo, como conceito

\footnotetext{
${ }^{25}$ Professores da educação básica, inclusive no Ensino Médio, tem maior propensão a ter mais de uma ocupação como forma de incrementar os rendimentos. No Brasil, Alves e Rezende (2011), com base em dados da PNAD (2009) argumentam que pouco mais de $10 \%$ do magistério nacional têm uma segunda ocupação. Piras e Savedoff (1998) justificam que se trata não só de docência em outros níveis de ensino, como eventualmente ocupações sem nenhuma relação com a área de atuação, como vendedores em lojas e funcionários em serviços de higiene e beleza. A fim de verificarmos a importância dos outros trabalhos na análise do diferencial de salários, as decomposições foram calculadas inicialmente para o logaritmo do rendimento-hora de todos os trabalhos e posteriormente comparadas com as decomposições utilizando somente o rendimento-hora do trabalho principal. Os resultados apresentavam variação somente no terceiro dígito das estimativas dos parâmetros, portanto, optamos por manter o rendimento do trabalho principal, evitando-se também a influência dos indivíduos que teriam a docência como ocupação secundária.
} 
de remuneração, preferimos recorrer ao salário horário do período presente.

Uma questão-chave é a construção dos grupos de comparação. Tradicionalmente, muitos trabalhos utilizam comparações dos salários de professores com categorias bastante amplas, tais como todos os funcionários do setor público ou todos os empregados do setor privado. Trabalhos recentes como Mizala e Ñopo (2011), Becker (2008) e Moriconi (2008) têm tentado empregar grupos de comparação tão homogêneos quanto possível. Neste trabalho, apresentamse ambos os tipos de comparações: com categorias amplas e com grupamentos ocupacionais com características similares, com base na Classificação Brasileira de Ocupações (CBO) domiciliar. Para a categoria que é base de comparação, dos professores do Ensino Médio, foi considerado apenas o código 2321, referente aos professores com formação de nível superior, uma vez que este é o grau mínimo de ensino exigido no Brasil para se lecionar no nível médio. Os demais grupamentos ocupacionais foram agregados em três diferentes grupos de comparação, conforme sintetizado na Tabela $1 .{ }^{26}$

Tabela 1 - Definições alternativas de não professores

\begin{tabular}{cccc}
\hline $\begin{array}{c}\text { Grupos de } \\
\text { comparação }\end{array}$ & Categorias incluídas & $\begin{array}{c}\text { Niveis de escolaridade } \\
\text { incluídos }\end{array}$ & Ocupações incluídas \\
\hline Grupo 1 & Funcionários públicos & Todos & $\begin{array}{c}\text { Exceto professores e trabalhadores } \\
\text { agricolas }\end{array}$ \\
Grupo 2 & $\begin{array}{c}\text { Empregados do setor } \\
\text { privado }\end{array}$ & Todos & $\begin{array}{c}\text { Exceto professores e trabalhadores } \\
\text { agrícolas }\end{array}$ \\
Grupo 3 & $\begin{array}{c}\text { Profissionais das ciências } \\
\text { eartes }\end{array}$ & Ensino Superior & Exceto profissionais do ensino \\
\hline
\end{tabular}

Os dois primeiros grupos se diferenciam apenas pelo setor de atuação - público e privado, exclusive professores e trabalhadores agrícolas. A hipótese de que a dinâmica salarial dos professores da rede pública, que representam a maior proporção dentre o total de professores do Ensino Médio (respectivamente, 75\% e 81\% em 2006 e 2009) seria próxima à de funcionários estatutários, justifica a escolha deste grupo de comparação.

${ }^{26}$ Os códigos das ocupações selecionadas das PNADs que serviram de base para formação dos grupos de professores e demais ocupaçóes podem ser disponibilizados se solicitados aos autores. 
Já o grupo formado pelos demais empregados do setor privado representa o grupo que proporciona o maior número de oportunidades ocupacionais alternativas à docência no mercado de trabalho como um todo (cf. Moriconi, 2008).

Nosso principal grupo de comparação, contudo, seguindo Becker (2008), é o grupo 3, denominado "profissionais das ciências e das artes", 27 representado por: engenheiros, físicos, químicos, matemáticos, profissionais da informática, arquitetos, médicos, veterinários, professores do ensino superior, advogados, juízes, pesquisadores, administradores, contadores, jornalistas, produtores, atores etc., que corresponde ao perfil que se busca atrair à carreira docente, qual seja, dos profissionais com melhor qualificação. Neste grupo a dinâmica salarial seria a mais próxima possível dos professores, uma vez que a escolaridade - aspecto em que professores e integrantes do grupo 3 se assemelham - é considerada um dos principais determinantes dos salários.

\subsection{Estatísticas Descritivas}

A Tabela 2 mostra que o logaritmo do rendimento horário médio do trabalho principal dos professores sofreu redução entre 2006 e 2009. Contrariamente, os valores para todas as demais categorias de trabalhadores apresentaram leve aumento. A remuneração dos profissionais das ciências, o principal grupo de comparação, aumentou, de modo que o diferencial entre as duas categorias passou de $8 \%$ em 2006, a 12\% em 2009. A situação dos professores é ainda mais preocupante quando se verifica que o diferencial médio favorável aos professores com relação às categorias dos demais funcionários públicos e empregados do setor privado (exceto professores) vem se reduzindo, respectivamente de $16 \%$ para $11 \%$ e de $38 \%$ para $33 \%$.

Como esperado, professores realmente trabalham menos horas que outros profissionais. A jornada de trabalho informada pelos professores indica que o trabalho docente tende a ser exercido, em média, por 130 a 133 horas mensais, respectivamente em 2006 e 2009, contra 159 e 158 horas para o terceiro grupo de comparação. Entretanto, deve-se considerar que os professores raramente declaram o número

${ }^{27}$ Categoria definida no contexto da Classificação Brasileira de Ocupações (CBO). 
de horas efetivamente trabalhadas, ou seja, horas dedicadas à preparação das aulas, correções de provas dentre outras atividades, em geral não são consideradas.

Também se observam importantes diferenças na comparação dos rendimentos das famílias dos professores e dos demais grupos ocupacionais. Dados da Tabela 2 sugerem que apesar de os professores viverem em famílias com renda média elevada, acima de $\mathrm{R} \$ 2.345$ em $2006,{ }^{28}$ sua situação relativa vem se deteriorando ao longo dos anos - em 2009, o rendimento total dos domicílios com professores foi de $\mathrm{R} \$ 2.066$, uma perda de 12\% sobre o poder de compra das famílias. Vale destacar que essa deterioração não foi observada em nenhum dos demais grupos de comparação nos anos analisados.

Um fator determinante nos salários dos docentes é a idade. Enquanto a idade média dos professores é de 39 anos, a dos profissionais de ciências é de 37 anos e dos demais empregados do setor privado é de 36 anos, o que sugere certo envelhecimento da população docente (funcionários públicos têm média de idade mais alta). Considerando que idade e experiência encontram-se estreitamente relacionadas e que, em geral, anos adicionais de experiência estão relacionados com aumentos salariais, seria de se esperar uma correlação positiva entre salário e idade. O que se observa é que, apesar de os docentes serem mais experientes e mais velhos que os profissionais das ciências, os primeiros recebem menores salários.

Da mesma forma, os anos de estudo também estão positivamente relacionados às habilidades dos indivíduos e, portanto à produtividade dos trabalhadores. Em 2009, enquanto a escolaridade média dos professores era de 14,8 anos, este número chegou a 11,9 anos no caso do funcionalismo público e 9,4 anos para os empregados do setor privado, com aumento do número de anos de estudo no triênio analisado para todos os grupos de comparação.

28 Valores expressos em reais de 2009. 


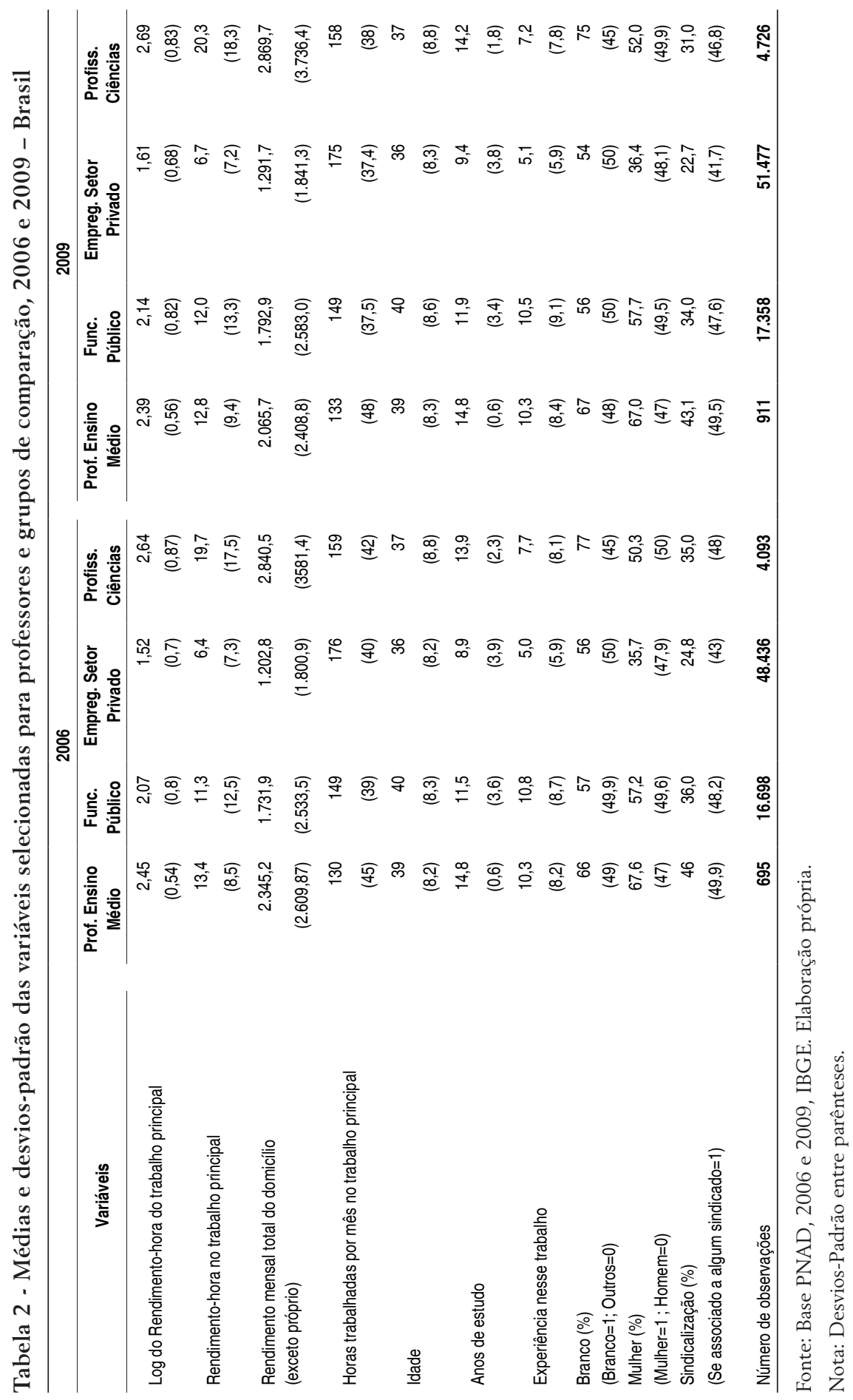


Do ponto de vista das características pessoais, a feminização da ocupação docente é evidente: $67 \%$ em 2009, contra 36\% a 58\% nas demais ocupações. Observa-se ainda que, ao contrário do que ocorreu na carreira docente, que apresentou leve redução no período analisado, as mulheres vêm aumentando sua participação relativa no mercado de trabalho entre 2006 e 2009 nas demais ocupações.

Por fim, os professores mantêm uma forte relação com os sindicatos, apesar de a taxa de sindicalização apresentar leve diminuição em três anos: de $46 \%$ para $43 \%$. Tal taxa - quase duas vezes maior que a dos empregados do setor privado - indicaria maior poder de barganha potencial de professores em sua luta por melhores salários e condições de trabalho, de forma que os salários médios, na ausência desse alto grau de sindicalização, poderiam ser ainda mais baixos.

\subsubsection{Estatísticas Descritivas Especificas à Técnica de Nopo (2008)}

Como dito anteriormente, optou-se pela inclusão de algumas variáveis que traduzissem características que poderiam influenciar a alocação dos trabalhadores entre a carreira docente versus demais ocupações. A escolha ocupacional pela carreira docente depende de vários aspectos como o custo do trabalho, a forma como o mercado é regulado (no caso dos professores, com elevada participação do Estado), os termos e condições de contratos além de potenciais barreiras a entrada (por exemplo, via validação de diplomas). Barbosa e Barbosa Filho (2012) apontam ainda que características como formação acadêmica e escolhas ocupacionais dos pais, dentre outras associadas ao background social e familiar, teriam forte impacto na escolha ocupacional feita pelos indivíduos.

Não obstante, bases tradicionalmente utilizadas para estimações de diferenciais salariais no Brasil, como PNAD e Censo, não possuem tais informações. A opção adotada aqui levou em conta variáveis utilizadas em estudos que adotaram a metodologia de Nopo (Daza e Gamboa, 2013; Mizala e Ñopo, 2012; Mizala e Nopo, 2011) ou que se preocuparam com a correção do viés de autosseleção dos trabalhadores (Barbosa e Barbosa Filho, 2012). 
A Tabela 3 apresenta as estatísticas descritivas para as variáveis consideradas em relação à decisão da escolha ocupacional em todos os grupos profissionais e para os dois períodos analisados.

Uma das principais variáveis a destacar refere-se à escolaridade dos grupos analisados. Os empregados do setor privado se tornaram mais bem qualificados ao longo do triênio analisado, uma vez que o percentual daqueles com ensino superior chegou a $1 / 5$ da força de trabalho em 2009. Contudo, reforça-se a distância entre estes e os professores do ensino médio e profissionais das ciências, respectivamente com 99\% e 90\% dos indivíduos com 12 ou mais anos de escolaridade.

Entre 2006 e 2009 é possível identificar, em todos os grupos profissionais, queda na proporção de domicílios com crianças menores de 14 anos. Contudo, os professores parecem estar, em média, em famílias com ao menos uma criança menor de 14 anos, embora a presença de crianças em domicílios de trabalhadores do setor privado e funcionários públicos seja mais elevada. Ainda em relação à ideia de responsabilidade financeira/dependência, os professores do ensino médio afirmam morar com pessoas mais velhas (65 anos ou mais) em proporção maior que os demais grupos. Tal resultado já havia sido identificado, para esta mesma categoria de professores em Mizala e Nopo (2012).

Além de residirem em domicílios onde há maior presença de idosos e crianças, os professores não são, em sua maioria, chefes de domicílio. Muitos convivem com outro membro no domicílio que exerce atividade remunerada. Tais características podem reforçar a ideia de que a escolha em se tornar professor estaria associada a um indivíduo que considera um estilo de vida no qual ter uma família e criar filhos tem relevância.

A proporção de professores que trabalham meio período (20 horas ou menos) não apresentou grandes oscilações no período, contudo, destaca-se o alto percentual de professores, mais que três vezes superior, ao de profissionais das ciências. No mais, nota-se que apesar do menor número de horas trabalhadas, quase $30 \%$ dos professores têm (ao menos) um segundo trabalho, percentual quase sete vezes maior comparado aos funcionários públicos em 2009. 
Em relação à distribuição espacial da força de trabalho, os professores do ensino médio estão sobrerrepresentados na região Sudeste. Entre os profissionais mais qualificados, $57 \%$ atuavam nessa região, contra apenas $15 \%$ localizados na região Nordeste.

Tabela 3 - Médias e desvios-padrão das variáveis selecionadas para professores e grupos de comparação, 2006 e 2009 - Brasil - Metodologia Nopo

\begin{tabular}{|c|c|c|c|c|c|c|c|c|}
\hline \multirow[b]{2}{*}{ Variáveis } & \multicolumn{4}{|c|}{2006} & \multicolumn{4}{|c|}{2009} \\
\hline & $\begin{array}{l}\text { Prof. Ensino } \\
\text { Médio }\end{array}$ & $\begin{array}{l}\text { Func. } \\
\text { Público }\end{array}$ & $\begin{array}{l}\text { Empreg. } \\
\text { Setor } \\
\text { Privado }\end{array}$ & $\begin{array}{l}\text { Profiss. } \\
\text { Ciências }\end{array}$ & $\begin{array}{l}\text { Prof. Ensino } \\
\text { Médio }\end{array}$ & $\begin{array}{l}\text { Func. } \\
\text { Público }\end{array}$ & $\begin{array}{l}\text { Empreg. } \\
\text { Setor } \\
\text { Privado }\end{array}$ & $\begin{array}{l}\text { Profiss. } \\
\text { Ciências }\end{array}$ \\
\hline \multirow{2}{*}{ Age_categ ${ }^{1}$} & 2,68 & 2,79 & 2,32 & 2,42 & 2,73 & 2,79 & 2,35 & 2,39 \\
\hline & $(1,04)$ & $(1,04)$ & $(1,09)$ & $(1,14)$ & $(1,06)$ & $(1,07)$ & $(1,10)$ & $(1,14)$ \\
\hline \multirow{2}{*}{ Ter_superior $^{2}$} & 99,0 & 46,1 & 17,2 & 81,9 & 99,0 & 51,8 & 20,1 & 89,4 \\
\hline & $(8,6)$ & $(49,9)$ & $(37,0)$ & $(38,7)$ & $(9,3)$ & $(49,9)$ & $(39,5)$ & $(31,1)$ \\
\hline \multirow{2}{*}{ nKid14 ${ }^{3}$} & 0,58 & 0,75 & 0,81 & 0,53 & 0,55 & 0,68 & 0,75 & 0,50 \\
\hline & $(0,75)$ & $(0,80)$ & $(0,81)$ & $(0,74)$ & $(0,72)$ & $(0,77)$ & $(0,79)$ & $(0,71)$ \\
\hline \multirow{2}{*}{ temAging $65^{4}$} & 15,6 & 11,9 & 9,6 & 12 & 15,0 & 12,0 & 10,1 & 12,3 \\
\hline & $(36,2)$ & $(31,9)$ & $(29,3)$ & $(31,7)$ & $(34,2)$ & $(31,8)$ & $(30,0)$ & $(32,5)$ \\
\hline \multirow{2}{*}{ Chefe $^{5}$} & 43,6 & 52,3 & 58,7 & 49,9 & 43,1 & 51,5 & 54,3 & 47,0 \\
\hline & $(49,7)$ & $(49,9)$ & $(49,2)$ & $(50,0)$ & $(49,6)$ & $(49,9)$ & $(49,8)$ & $(49,9)$ \\
\hline \multirow{2}{*}{ numpeswork_dom ${ }^{6}$} & 44,6 & 42,5 & 38,3 & 45,6 & 48,4 & 44,7 & 41,3 & 47,5 \\
\hline & $(49,8)$ & $(49,5)$ & $(48,6)$ & $(49,9)$ & $(50,0)$ & $(49,7)$ & $(49,1)$ & $(49,9)$ \\
\hline \multirow{2}{*}{ parttime $^{7}$} & 13,1 & 7,1 & 2,7 & 4,8 & 13,0 & 6,6 & 2,3 & 4,1 \\
\hline & $(33,6)$ & $(25,3)$ & $(16,4)$ & $(21,5)$ & $(34,0)$ & $(24,5)$ & $(15,3)$ & $(20,1)$ \\
\hline \multirow{2}{*}{ maisdeumtrabalho ${ }^{8}$} & 27,7 & 12,4 & 3,8 & 13,9 & 26,9 & 12,0 & 3,9 & 13,2 \\
\hline & $(44,6)$ & $(32,3)$ & $(19,1)$ & $(34,8)$ & $(44,6)$ & $(32,2)$ & $(19,9)$ & $(34,8)$ \\
\hline \multirow{2}{*}{ NORTE } & 7,2 & 8,8 & 5,4 & 4,8 & 8,0 & 9,5 & 5,3 & 4,3 \\
\hline & $(33,6)$ & $(36,2)$ & $(29,7)$ & $(29,3)$ & $(35,1)$ & $(36,6)$ & $(29,3)$ & $(27,5)$ \\
\hline \multirow{2}{*}{ NORDESTE } & 23,7 & 25,6 & 17,6 & 15,3 & 22,4 & 25,4 & 17,7 & 15,1 \\
\hline & $(45,1)$ & $(44,9)$ & (43) & $(41,5)$ & $(44,4)$ & $(44,8)$ & $(43,1)$ & $(41,0)$ \\
\hline \multirow{2}{*}{ SUDESTE } & 45,9 & 42,4 & 53,2 & 57,9 & 46,2 & 41,6 & 53,2 & 56,8 \\
\hline & $(45,6)$ & $(45,0)$ & $(48,1)$ & $(48,5)$ & $(45,9)$ & $(44,9)$ & $(48,1)$ & $(48,6)$ \\
\hline \multirow{2}{*}{ SUL } & 14 & 14,0 & 17,0 & 14,2 & 13,2 & 13,8 & 16,7 & 15,5 \\
\hline & $(35,9)$ & $(34,5)$ & $(38,9)$ & $(36,9)$ & $(33,8)$ & $(34,2)$ & $(38,8)$ & $(38,1)$ \\
\hline \multirow{2}{*}{ CENTRO-OESTE } & 9,2 & 9,2 & 6,9 & 7,8 & 10,2 & 9,7 & 7,0 & 8,4 \\
\hline & $(34,9)$ & $(35,1)$ & $(31,0)$ & $(35,0)$ & $(36,0)$ & $(35,5)$ & $(31,3)$ & $(35,3)$ \\
\hline
\end{tabular}

Fonte: Base PNAD, 2006 e 2009, IBGE. Elaboração própria. Desvios-Padrão entre parênteses. Notas: ${ }^{1} 1=$ menor ou igual 30 anos; $2=$ maior que 30 anos e menor ou igual a 35 anos; $3=$ maior que 35 anos e menor ou igual a 45 anos; 4 = maior que 45 anos e menor ou igual a 55 anos; ${ }^{2} 1$ = ensino superior incompleto, completo ou pós-graduação (acima de 11 anos de estudo), 0 caso contrário. ${ }^{3} 1$ = apenas uma criança menor de 14 anos; 2 = mais de uma criança menor de 14 anos; $0=$ domicílio não possui crianças menores de 14 anos; ${ }^{4} 1=$ tem pessoas maiores que 65 anos, 0 caso contrário; ${ }^{5} 1=$ chefe de família, 0 caso contrário; ${ }^{6} 1=$ mais de uma pessoa no domicílio exercia algum trabalho na semana de referência, $0=$ apenas uma pessoa no domicílio exercia trabalho na sema na de referência; ${ }^{7} 1=$ trabalha menos de 20 horas por semana; ${ }^{8} 1=$ tinha mais de um trabalho na semana de referência, 0 caso contrário. 


\section{Resultados e Discussão}

\subsection{Decomposições de Oaxaca-Blinder}

Por não ser o foco do artigo, omitimos os resultados das equações de salário propriamente ditas, ${ }^{29}$ para nos concentrarmos sobre os resultados das decomposições, tanto as tradicionais de Oaxaca-Blinder, quanto as mais sofisticadas, seguindo Nopo (2008).

No que se refere à comparação entre professores do Ensino Médio e funcionários públicos (exceto professores), o hiato é favorável aos professores em ambos os anos (Tabela 4: Painel A). Em 2006, os salários dos professores eram 15,5\% maiores que aqueles auferidos pelos funcionários públicos; já em 2009, esta vantagem diminuiu para $10,5 \%$. Portanto, mesmo quando comparados com um grupo bastante heterogêneo como o dos funcionários públicos, os professores têm visto sua vantagem, em termos salariais, reduzir-se em razão de tênue redução do potencial explicativo das características (que se altera marginalmente de 2006 para 2009) e de forte incremento em prol de não professores da parcela devida aos coeficientes.

Não temos como afirmar a que se deve esta fração explicada por coeficientes. Poderia se dever a alguma heterogeneidade fora do suporte comum, capturável com a metodologia de Ñopo (2008) ou por variáveis omitidas (inclusive características não observadas que explicariam escolha ocupacional e que também seriam remuneradas no mercado de trabalho). Contudo, tais explicações plausíveis esbarram no seguinte problema: por que os coeficientes não eram importantes em 2006 e ganham relevância em 2009? Por que heterogeneidade e seleção não teriam importância num ano, mas sim em outro?

Assim como na comparação entre professores e funcionários públicos, o diferencial de salários é novamente favorável aos professores na

\footnotetext{
${ }^{29}$ Resultados obteníveis por meio de contato com os autores.

De modo geral, diga-se apenas que variáveis como escolaridade, experiência e idade não apresentam forte poder de explicação sobre o salário dos professores, ao contrário do que ocorre com as demais categorias de trabalhadores, para as quais essas variáveis são estatisticamente significativas. Já o impacto da localização reforça o aspecto negativo com relação aos professores que atuam na região Nordeste, cujos docentes recebem menores salários. Uma boa notícia é que esta "penalidade" vem perdendo força ao longo dos anos, possível efeito inicial da implantação do FUNDEB na redução da desigualdade entre os docentes do nível médio.
} 
comparação com empregados do setor privado (Tabela 4: Painel B). $\mathrm{Na}$ média, os professores recebiam $38,0 \%$ mais que os empregados do setor privado em 2006, vantagem esta que também vem diminuindo ao longo do tempo e chega a 32,6\% em 2009. É importante ressaltar que este grupo é o que apresenta a maior diferenciação em relação às características sociodemográficas dos professores: baixa escolaridade, pouco tempo de atuação na ocupação exercida e menor idade. O diferencial pode ser atribuído em maior medida às características observáveis, sem alterações entre 2006 e 2009 (representam pouco mais de $2 / 3$ do diferencial de salários em ambos os anos estudados), mas também aos coeficientes, que respondem por cerca de $1 / 3$ do diferencial em cada um dos anos.

Este último resultado é intrigante, pois o esperado é que estivessem mais próximos de zero. Entre as possíveis explicações, destacam-se: (i) possíveis variáveis omitidas, uma vez que trabalhamos com um conjunto tão grande quanto possível de variáveis, mas, ainda assim, limitado - pode ser que, de posse de uma base mais completa, mais pudesse ser explicado pelas características observáveis, (ii) considerável heterogeneidade entre professores e não professores nas comparações apresentadas sobretudo neste Painel B.

Não há muito a fazer com relação ao problema (i), a não ser utilizar outras bases, em estudos alternativos, para investigar melhor a questão. Já o problema (ii) nos serve de motivação, tanto para justificar a comparação seguinte, ainda com Oaxaca-Blinder - que toma como grupo de comparação os profissionais das ciências e das artes, grupo cujas características são mais próximas às dos professores - como os resultados a serem apresentados na subseção seguinte, baseados na metodologia de Ñopo (2008), que proporciona decomposição mais fina do diferencial. 
Tabela 4 -Evolução do diferencial salarial entre grupos de comparação e professores e da análise de decomposição de Oaxaca-Blinder (Brasil, 2006 e 2009)

Painel A: Funcionários públicos (exceto professores) versus professores do Ensino Médio

\begin{tabular}{|c|c|c|}
\hline & 2006 & 2009 \\
\hline $\begin{array}{l}\text { Características observáveis (idade, raça, gênero, anos de estudo, experiência } \\
\text { nesse trabalho, região) } \\
\text { Coeficientes (parcela não explicada) }\end{array}$ & $\begin{array}{c}-0,3895 \\
0,0088\end{array}$ & $\begin{array}{l}-0,3644 \\
0,1009\end{array}$ \\
\hline Diferencial salarial & $\begin{array}{c}-0,3807 \\
(-15,5 \%)\end{array}$ & $\begin{array}{l}-0,2635 \\
(-10,5 \%)\end{array}$ \\
\hline \multicolumn{3}{|c|}{ Painel B: Empregados do setor privado (exceto professores) versus professores do Ensino Médio } \\
\hline & 2006 & 2009 \\
\hline $\begin{array}{l}\text { Características observáveis (idade, raça, gênero, anos de estudo, experiência } \\
\text { nesse trabalho, região) } \\
\text { Coeficientes (parcela não explicada) }\end{array}$ & $\begin{array}{l}-0,6349 \\
-0,2926\end{array}$ & $\begin{array}{l}-0,5356 \\
-0,2476\end{array}$ \\
\hline Diferencial salarial & $\begin{array}{c}-0,9275 \\
(-38,0 \%)\end{array}$ & $\begin{array}{c}-0,7832 \\
(-32,6 \%)\end{array}$ \\
\hline \multicolumn{3}{|c|}{ Painel C: Profissionais das ciências e das artes versus professores do Ensino Médio } \\
\hline & 2006 & 2009 \\
\hline $\begin{array}{l}\text { Características observáveis (idade, raça, gênero, anos de estudo, experiência } \\
\text { nesse trabalho, região) } \\
\text { Coeficientes (parcela não explicada) }\end{array}$ & $\begin{array}{c}-0,1776 \\
0,3760\end{array}$ & $\begin{array}{r}-0,1840 \\
0,4840\end{array}$ \\
\hline Diferencial salarial & $\begin{array}{l}0,1984 \\
(7,8 \%)\end{array}$ & $\begin{array}{c}0,3000 \\
(12,6 \%)\end{array}$ \\
\hline
\end{tabular}

Fonte: Elaboração própria utilizando dados da PNAD (IBGE, 2006 e 2009).

Nota: Resultados obtidos a partir da Equação 1.

Na comparação entre professores do Ensino Médio e profissionais das ciências e das artes - como dito acima, o grupo mais semelhante para comparação -, o diferencial de salários, favorável em ambos os períodos aos não professores, aumentou de forma significativa. Se em 2006 os salários dos profissionais das ciências eram 7,8\% maior que dos professores, em 2009 tal vantagem alcança 12,6\% (Tabela 4: Painel C). Em ambos os anos, se dependesse somente das diferenças em termos de características observáveis, o diferencial seria favorável aos professores; contudo, a parcela não explicada é extremamente acentuada, mais do que compensando a vantagem em termos de características observáveis dos professores. 


\subsection{Decomposições de Ñopo}

Os resultados baseados na metodologia de Oaxaca-Blinder podem ser criticados por efetuarem comparação fora do suporte comum de características, tal como apontado por Ñopo. Por esta razão, aplicamos a metodologia proposta por este autor, a fim de distinguir o que se deve a diferenças entre grupos (fora do suporte comum de características) e o que se deve, somente dentro do suporte comum, às características observáveis e à parte não explicada. Nos próximos parágrafos apresenta-se o diferencial "bruto" entre professores e cada um dos grupos de comparação (denominado Delta) seguido dos diferenciais que se mantêm após controlar-se para cada uma das covariadas. $\mathrm{Na}$ última linha da tabela, professores e não professores estão sendo comparados levando em conta o conjunto completo de características observáveis.

Na comparação entre professores e funcionários públicos (Painel A), praticamente a totalidade do diferencial favorável aos professores, seja em 2006, seja em 2009, deve-se à existência de características diferentes entre professores e não professores (delta NP), ou seja, existem combinações de características identificadas entre os professores, que não existem entre não professores. Para se ter uma ideia, a adição do componente "ter ensino superior" reduz a amostra de não professores no suporte comum em 47\% (CS_NP) em ambos os anos, enquanto na presença do conjunto completo de variáveis, apenas 1 a cada 10 indivíduos que atuam no setor público tem a mesma combinação de características que os professores, em ambos os anos.

Ressalte-se ainda que, dentro do suporte comum, as características observáveis (delta $\mathrm{X}$ ) pouco explicam a vantagem dos professores ao longo do triênio analisado, à exceção de características relacionadas à família e ao trabalho, as quais acabam por atenuar a vantagem em favor dos professores. Em relação à parcela do diferencial explicada pelos coeficientes (delta $\mathrm{O}$ ), observa-se inversão de sinal entre os anos: passa-se de contribuição favorável aos professores em 2006 para desfavorável em 2009.

Este resultado para 2009 acompanha aquele encontrado na decomposição de Oaxaca-Blinder e discutido quando da apresentação da Tabela 4: Painel A, contudo, em escala menor, uma vez que a proporção explicada por coeficientes cai de $38 \%$ com Nopo para $28 \%$ com Oaxaca-Blinder. ${ }^{30}$ 
Em relação aos empregados do setor privado (Tabela 5: Painel B), grosso modo, a totalidade do diferencial salarial deve-se a características diferentes entre os indivíduos que compõem os grupos analisados (deltaNP) em 2006. Neste caso, fica claro o problema com o modelo Oaxaca-Blinder: o que era creditado a diferentes características, na realidade, escondia uma comparação entre indivíduos completamente diferentes. Fato é que ao incluir-se o conjunto total de variáveis, apenas $7 \%$ dos funcionários públicos permanecem na amostra (coluna CS_NP). Assim, o problema que nos intrigava com o modelo anterior deixa de existir: não temos mais coeficientes que explicam 1/3 do diferencial total; agora, sua importância é diminuta (2,7\%). A metodologia de Ñopo (2008) possibilitou maior precisão na análise.

Em 2009, mais uma vez, grande parte do diferencial pró-professores deve-se a características diferentes entre professores e não professores (delta NP), porém com tendência decrescente, possivelmente em virtude da melhora das características deste grupo, com destaque para a educação. Em 2006, apenas 37\% dos empregados do setor privado encontravam-se no suporte comum ao incluirmos essa característica, enquanto em 2009 este percentual atingiu quase metade deste grupo.

Dentro do suporte comum, a inclusão das características observáveis relacionadas à composição familiar e ao trabalho tem influência bastante significativa (e crescente ao longo dos anos) na explicação do diferencial. Ao incluirmos todas as variáveis, exceto a de localização, cujo efeito reduz bastante a importância das características observáveis, estas explicavam quase um quinto do diferencial favorável a professores. Mais uma vez, em relação à decomposição OaxacaBlinder, reduziu-se bastante a importância dos coeficientes, os quais passam, com Nopo, a responder por apenas $8 \%$ do diferencial em favor dos professores em 2009.

\footnotetext{
${ }^{30}$ A queda no componente não explicado pode ser resultado de mudanças na própria distribuição das características observáveis entre os grupos analisados ao longo do tempo. Nopo (2012) argumenta que diferenciais salariais não explicados entre professores e demais grupos de comparação poderiam estar relacionados a diferenças ao longo da distribuição de renda dos grupos analisados: professores nos percentis mais altos de renda ganhariam menos que outros profissionais enquanto professores nos percentis mais baixos teriam ganhos similares ou até mesmo superiores que os grupos de comparação.
} 
O primeiro ponto a se destacar na comparação com o grupo dos profissionais das ciências e das artes (Tabela 5: Painel C) é que a proporção de não professores pareados (CS_NP) é bastante superior àquelas observadas na duas comparações anteriores (Painéis A e B), reforçando a hipótese de melhor adequação deste terceiro conjunto de indivíduos como grupo de comparação.

Para 2006, as diferenças devidas a características observáveis, anteriormente apontadas como importantes na decomposição OaxacaBlinder, mostram-se espúrias, por se basearem em diferenças externas ao suporte comum. Dentro deste, o diferencial favorável a não professores é inteiramente determinado pela parcela não explicada (delta O). Isto pode se dever a variáveis omitidas de diferentes naturezas:

- Discriminação: pouco plausível neste contexto;

- Baixa valorização social de professores, uma vez que grande dos professores têm salários determinados pelo setor público;

- Níveis preexistentes de produtividade distintos (isto é, pré-escolha ocupacional). Poderia ter ocorrido autosseleção para um grupo ou outro em função de características não observáveis que proporcionariam, no futuro, prêmios diferentes no mercado de trabalho;

- Níveis de produtividade distintos desenvolvidos pós-escolha ocupacional, não observáveis na base de dados de que dispomos, e remuneradas distintamente no mercado de trabalho.

Por fim, em 2009, observa-se quadro semelhante ao de 2006, com características fora do suporte comum favoráveis a professores. Dentro do suporte, as características observáveis moderam um pouco o hiato pró-não professores, mas o componente primordial continua sendo o de coeficientes, e as hipóteses para explicar isto são as mesmas apontadas acima. 
Tabela 5 - Evolução do diferencial salarial entre grupos de comparação e professores e da análise de decomposição de Nopo (Brasil, 2006 e 2009)

\begin{tabular}{|c|c|c|c|c|c|c|c|c|c|c|c|c|}
\hline \multirow{4}{*}{ Variáveis } & \multicolumn{6}{|c|}{2006} & \multicolumn{6}{|c|}{2009} \\
\hline & \multicolumn{12}{|c|}{ Painel A - Funcionários públicos (exceto professores) versus professores do Ensino Médio } \\
\hline & \multicolumn{6}{|c|}{ Delta $=-18,4 \%$} & \multicolumn{6}{|c|}{ Delta $=-13,2 \%$} \\
\hline & Delta 0 & Delta NP & Delta P & Delta X & CS_NP & CS_P & Delta 0 & Delta NP & Delta P & Delta X & CS_NP & CS_P \\
\hline Gênero & $-0,185$ & - & - & 0,001 & 1,000 & 1,000 & $-0,137$ & - & - & 0,005 & 1,000 & 1,000 \\
\hline+ Cor & $-0,161$ & - & - & $-0,023$ & 1,000 & 1,000 & $-0,111$ & - & - & $-0,021$ & 1,000 & 1,000 \\
\hline + Age_categ & $-0,179$ & - & - & $-0,005$ & 1,000 & 1,000 & $-0,123$ & - & - & $-0,009$ & 1,000 & 1,000 \\
\hline + Ter_superior & $-0,022$ & $-0,134$ & - & $-0,028$ & 0,53 & 1,000 & 0,016 & $-0,146$ & - & $-0,002$ & 0,53 & 1,000 \\
\hline + nKid14 & $-0,019$ & $-0,163$ & - & $-0,002$ & 0,45 & 1,000 & 0,019 & $-0,155$ & - & 0,004 & 0,45 & 1,000 \\
\hline + temAging65 & $-0,024$ & $-0,167$ & - & 0,007 & 0,43 & 1,000 & 0,016 & $-0,162$ & - & 0,014 & 0,42 & 1,000 \\
\hline+ Chefe & $-0,026$ & $-0,180$ & 0,000 & 0,022 & 0,37 & 0,99 & 0,012 & $-0,165$ & - & 0,021 & 0,36 & 1,000 \\
\hline + numpeswork_dom & $-0,032$ & $-0,178$ & 0,001 & 0,025 & 0,30 & 0,99 & 0,014 & $-0,158$ & - & 0,012 & 0,30 & 1,000 \\
\hline + parttime & $-0,041$ & $-0,180$ & 0,001 & 0,036 & 0,26 & 0,95 & 0,008 & $-0,158$ & 0,002 & 0,016 & 0,26 & 0,99 \\
\hline + maisdeumtrabalho & $-0,036$ & $-0,171$ & 0,002 & 0,021 & 0,19 & 0,94 & 0,004 & $-0,149$ & $-0,001$ & 0,014 & 0,19 & 0,98 \\
\hline + Região & $-0,041$ & $-0,179$ & 0,002 & 0,034 & 0,09 & 0,83 & 0,037 & $-0,148$ & $-0,015$ & $-0,006$ & 0,08 & 0,88 \\
\hline
\end{tabular}

Painel B - Empregados do setor privado (exceto professores) versus professores do Ensino Médio

\begin{tabular}{|c|c|c|c|c|c|c|c|c|c|c|c|c|}
\hline \multirow{3}{*}{ Variáveis } & \multirow{2}{*}{\multicolumn{6}{|c|}{ Delta $=-37,0 \%$}} & \multirow{2}{*}{\multicolumn{6}{|c|}{ Delta $=-32,2 \%$}} \\
\hline & & & & & & & & & & & & \\
\hline & Delta 0 & Delta NP & Delta P & Delta X & CS_NP & CS_P & Delta 0 & Delta NP & Delta P & Delta X & CS_NP & CS_P \\
\hline Gênero & $-0,388$ & - & - & 0,018 & 1,000 & 1,000 & $-0,34$ & - & - & 0,018 & 1,000 & 1,000 \\
\hline+ Cor & $-0,382$ & - & - & 0,012 & 1,000 & 1,000 & $-0,327$ & - & - & 0,005 & 1,000 & 1,000 \\
\hline + Age_categ & $-0,373$ & - & - & 0,003 & 1,000 & 1,000 & $-0,321$ & - & - & $-0,001$ & 1,000 & 1,000 \\
\hline + Ter_superior & $-0,050$ & $-0,102$ & - & $-0,218$ & 0,37 & 1,000 & $-0,054$ & $-0,079$ & - & $-0,189$ & 0,49 & 1,000 \\
\hline + nKid14 & $-0,052$ & $-0,200$ & - & $-0,118$ & 0,25 & 1,000 & $-0,052$ & $-0,145$ & - & $-0,125$ & 0,31 & 1,000 \\
\hline+ temAging 65 & $-0,055$ & $-0,210$ & - & $-0,105$ & 0,23 & 1,000 & $-0,055$ & $-0,152$ & - & $-0,115$ & 0,30 & 1,000 \\
\hline+ Chefe & $-0,050$ & $-0,248$ & $-0,001$ & $-0,071$ & 0,20 & 0,99 & $-0,049$ & $-0,178$ & - & $-0,095$ & 0,26 & 1,000 \\
\hline + numpeswork_dom & $-0,052$ & $-0,260$ & $-0,001$ & $-0,057$ & 0,17 & 0,99 & $-0,053$ & $-0,210$ & $-0,001$ & $-0,058$ & 0,21 & 0,99 \\
\hline + parttime & $-0,034$ & $-0,258$ & $-0,003$ & $-0,075$ & 0,16 & 0,97 & $-0,041$ & $-0,226$ & $-0,003$ & $-0,052$ & 0,19 & 0,97 \\
\hline + maisdeumtrabalho & $-0,013$ & $-0,331$ & - & $-0,026$ & 0,12 & 0,93 & $-0,019$ & $-0,239$ & $-0,004$ & $-0,06$ & 0,17 & 0,94 \\
\hline + Região & $-0,010$ & $-0,371$ & 0,003 & 0,008 & 0,07 & 0,80 & $-0,026$ & $-0,263$ & $-0,005$ & $-0,028$ & 0,09 & 0,82 \\
\hline
\end{tabular}

Painel C - Profissionais das ciências e das artes versus professores do Ensino Médio

\begin{tabular}{|c|c|c|c|c|c|c|c|c|c|c|c|c|}
\hline \multirow[t]{2}{*}{ Variáveis } & \multicolumn{6}{|c|}{ Delta $=8,2 \%$} & \multicolumn{6}{|c|}{ Delta $=12,5 \%$} \\
\hline & Delta 0 & Delta NP & Delta P & Delta X & CS_NP & CS_P & Delta 0 & Delta NP & Delta P & Delta X & CS_NP & CS_P \\
\hline Gênero & 0,061 & - & - & 0,021 & 1,000 & 1,000 & 0,108 & - & - & 0,017 & 1,000 & 1,000 \\
\hline+ Cor & 0,043 & - & - & 0,039 & 1,000 & 1,000 & 0,099 & - & - & 0,026 & 1,000 & 1,000 \\
\hline + Age_categ & 0,064 & - & - & 0,018 & 1,000 & 1,000 & 0,122 & - & - & 0,003 & 1,000 & 1,000 \\
\hline + Ter_superior & 0,138 & $-0,050$ & - & $-0,006$ & 0,87 & 1,000 & 0,169 & $-0,025$ & - & $-0,019$ & 0,93 & 1,000 \\
\hline + nKid14 & 0,137 & $-0,059$ & - & 0,004 & 0,84 & 1,000 & 0,167 & $-0,036$ & - & $-0,006$ & 0,90 & 1,000 \\
\hline + temAging65 & 0,131 & $-0,061$ & - & 0,012 & 0,83 & 0,99 & 0,163 & $-0,037$ & - & $-0,001$ & 0,90 & 1,000 \\
\hline + Chefe & 0,138 & $-0,066$ & - & 0,010 & 0,80 & 0,98 & 0,165 & $-0,037$ & - & $-0,003$ & 0,87 & 0,99 \\
\hline + numpeswork_dom & 0,130 & $-0,064$ & - & 0,016 & 0,75 & 0,97 & 0,161 & $-0,036$ & 0,001 & $-0,001$ & 0,82 & 0,98 \\
\hline + parttime & 0,139 & $-0,062$ & $-0,001$ & 0,006 & 0,72 & 0,93 & 0,167 & $-0,037$ & 0,001 & $-0,006$ & 0,80 & 0,94 \\
\hline + maisdeumtrabalho & 0,154 & $-0,063$ & $-0,004$ & $-0,005$ & 0,66 & 0,86 & 0,182 & $-0,036$ & $-0,003$ & $-0,018$ & 0,75 & 0,89 \\
\hline + Região & 0,155 & $-0,072$ & $-0,001$ & - & 0,43 & 0,67 & 0,196 & $-0,037$ & $-0,005$ & $-0,029$ & 0,49 & 0,73 \\
\hline
\end{tabular}

Fonte: Cálculos dos autores a partir da PNAD $(2006,2009)$. 


\section{Considerações Finais}

A percepção generalizada de que os professores são mal remunerados é assunto frequente na literatura que trata da qualidade da educação. A hipótese de que melhores salários tornariam a profissão mais atrativa aos jovens, sobretudo para aqueles com melhor qualificação - o que afetaria positivamente o nível de aprendizado dos alunos no Brasil - é sempre acompanhada de discussões entusiásticas envolvendo educadores, economistas e demais pesquisadores que analisam o assunto. Contribuindo para esse debate, neste estudo investigamos se os salários dos professores no Ensino Médio são similares aos dos profissionais de três grupos de comparação, a partir da PNAD para os anos de 2006 e 2009, e decompusemos os diferenciais, produzindo resultados originais e complementares aos da literatura nacional.

Uma análise preliminar indica que a impressão generalizada de que os professores são malremunerados vem afetando não somente a oferta de professores, mas principalmente de professores qualificados. O perfil dos ingressantes na carreira segue padrão preocupante: jovens provenientes de famílias de baixa renda, pouca escolaridade, que frequentaram todo o Ensino Médio em escola pública e que tiveram poucas oportunidades culturais. Ou seja, são jovens que disputam, dadas suas limitações, o direito ao acesso a carreiras pouco concorridas.

Por meio de análise quantitativa, constata-se que os professores do Ensino Médio possuem diferencial salarial favorável somente quando comparados com indivíduos com níveis médios de escolaridade mais baixos (setor público ou privado). Todavia, a vantagem dos professores com relação aos grupos de menor escolaridade e experiência média vem diminuindo. O emprego de uma nova técnica não paramétrica (de Nopo) permite uma decomposição mais fina do diferencial salarial, isolando efeitos dentro e fora dos suportes comuns. Em relação aos grupos de funcionários públicos e empregados do setor privado, o que se credita, na decomposição tradicional (de Oaxaca-Blinder), a diferentes características, na realidade, representa comparação entre indivíduos muito diferentes. 
Os profissionais das ciências e das artes revelam ser o grupo mais comparável aos professores, o que é atestado com o uso da técnica mais refinada, e, neste caso, o diferencial de remuneração é sempre desfavorável aos professores, e parece seguir tendência de aumento. Ambas as técnicas de decomposição indicam que professores não são devidamente recompensados no mercado de trabalho por sua escolaridade relativamente elevada, uma vez que o diferencial salarial deve-se, em grande medida, a diferenças em características não observáveis. É plausível supor que isto se reflita no baixo interesse dos jovens mais bem qualificados ao final do Ensino Médio pelas carreiras de pedagogia e licenciaturas - ainda que o sentido em que opera a causalidade seja uma questão em aberto, fora do escopo deste artigo, porém digna de ser objeto de pesquisas futuras.

De modo geral, portanto, aparentemente os efeitos da ampliação do FUNDEF para o FUNDEB, incorporando professores que atuam no ensino médio, sobre o crescimento dos salários dos professores não foram verificados no período, ao contrário dos resultados verificados para os professores do ensino fundamental quando da implantação do FUNDEF. ${ }^{31}$ Uma possível causa pode estar atrelada ao pouco tempo transcorrido entre a implantação do fundo (assim como da lei do piso salarial nacional) e a avaliação dos dados apresentada neste artigo. De fato, a Lei 11.738/2008, que previa, além da regulamentação de um piso salarial nacional para os profissionais do magistério público da educação básica, melhores condições de trabalho, ainda não foi adotada integralmente pelos Estados e municípios brasileiros.

Tomando o grupo dos profissionais das ciências e das artes como nosso principal grupo de comparação, alguns dos resultados apresentados neste estudo são preocupantes. Uma estrutura salarial que não favorece indivíduos com níveis mais altos de educação acaba por penalizar justamente aqueles profissionais que mais se quer atrair, os quais acabam encontrando melhores oportunidades em outras ocupações.

Além disso, o aumento dos programas de responsabilização de professores, o excesso de horas trabalhadas fora da sala de aula (jornada não necessariamente reconhecida, nem captada em pesquisas domiciliares), a alegada piora no comportamento dos alunos e nas condições

${ }^{31}$ Anuatti-Neto et al. (2004) verificaram um aumento salarial obtido pelos professores do ensino fundamental em torno de $30 \%$, superior aos ganhos auferidos pelos funcionários públicos (e empregados do setor privado). 
de segurança nas escolas brasileiras, períodos de férias gradualmente reduzidos, podem estar fazendo com que fatores não pecuniários percam espaço como aspectos compensadores da menor remuneração mensal na escolha ocupacional pela docência. Por fim, com o advento das novas regras previdenciárias, a atratividade da docência no setor público em particular poderá reduzir-se ainda mais.

Em vista de tudo isso, as perspectivas de se conseguir atrair os melhores alunos do Ensino Médio para as carreiras da educação - o que requer retomada do prestígio da profissão, incluindo melhores condições de trabalho e recuperação salarial da profissão - não são muito encorajadoras.

\section{Referências}

AKERLOF, G. A.; KRANTON R. E., Economics and Identity, Quarterly Journal of Economics, 115, 2000.

ALVES, THIAGO; REZENDE PINTO, JOSÉ MARCELINO. Análise das características do trabalho e da remuneração docente no Brasil a partir de dados demográficos e educacionais, Anais do XXXIV Reunião Anual da Associação Nacional de Pós-Graduação e Pesquisa em Educação ANPED, Natal - RN, 2011. Disponível em: http://34reuniao.anped.org.br/images/trabalhos/GT05/ GT05-735\%20int.pdf. Acesso em 11 nov. 2011.

ANUATTI-NETO, FRANCISCO; FERNANDES, REYNALDO; PAZELLO, ELAINE T.; Avaliação dos salários dos professores da rede pública do ensino fundamental em tempos de FUNDEF, Revista de Economia Aplicada, v.8, no.3, pp. 413-437, 2004.

ASADULLAH, M.N. Pay differences between teachers and other occupations: some empirical evidence from Bangladesh, Journal of Asian Economics, Oxford, v.17, n.6, pp. 1044-1065, 2006.

BARBER, MICHAEL; MOURSHED, MONA. How the world's best performing school systems come out on top. Mc Kinsey, 2007.

BARBOSA, A. L. N. H. ; BARBOSA-FILHO, F. H. ; LIMA, J. R. F. Diferencial de salários e determinantes na escolha de trabalho entre os setores público e privado no Brasil. Pesquisa e Planejamento Econômico (Rio de Janeiro), v. 43, p. 89-118, 2013.

BARBOSA-FILHO, F.H.; PESSÔA, S.A.; AFONSO, L. E. Um estudo sobre os diferenciais de remuneração entre os professores das redes pública e privada de ensino. Revista de Estudos Econômicos, v. 39, no.3, pp. 597-628, São Paulo, 2009.

BARROS, R. P., MENDONÇA R., BLANCO, M. O mercado de trabalho para professores no Brasil. Anais do XXIX Encontro Nacional de Economia - ANPEC, Salvador-BA, 2001.

BAUMOL, W.J; Health care, education and the cost disease: A looming crisis for public choice, Public Choice, vol. 77, pp. 17-28, 1993.

BECKER, K. L. A remuneração do trabalho do professor no ensino fundamental público brasileiro. 124 f. Dissertação (Mestrado em Economia), Escola Superior de Agricultura Luiz de Queiroz, Universidade de São Paulo, São Paulo, 2008.

BLINDER, A. "Wage Discrimination: Reduced Form and Structural Estimates." The Journal of Human Resources, VII, 4, pp. 436-55, 1973. 
BOWLES, SAMUEL. Microeconomics: Behavior, Institutions and Evolution, Princeton University Press, pp. 93-126, 2004.

BRASIL. MINISTÉRIO DA EDUCAÇÃO. Resolução no. 2, de 28 de Maio de 2009. Fixa as Diretrizes Nacionais para os Planos de Carreira e Remuneração dos Profissionais do Magistério da Educação Básica Pública. Diário Oficial da União, seção 1, pp. 41 e 42, 2009.

BRASIL. MINISTÉRIO DA EDUCAÇÃO. Lei 11.738, de 16 de Julho de 2008. Disponível em: https:// www.planalto.gov.br/ccivil_03/_ato2007-2010/2008/lei/111738.htm. Acesso em: 14 ago. 2011, 2008 .

CHANDUVÍ, J. S.. La situación laboral de los maestros respecto de otros profesionales. Implicancias para el diseño de políticas salariales y de incentivos. In: Es posible mejorar la educación peruana, Evidencias y Posibilidades, Patricia Arregui (ed.), GRADE Grupo de Análisis para el Desarrollo, Lima, Peru, pp.181-246, 2004.

COTTON, J., On the decomposition of wage differentials, Review of Economics and Statistics, v.70, no.2, p.236-243, 1988.

DAZA, N.; GAMBOA, L. An approximation to the Informal-formal wage gap in Colombia 2008-2012. Universidad del Rosario, Facultad de Economía, Documento de trabajo no. 138, pp. 91, 2013.

FUNDAÇÃO CARLOS CHAGAS, A atratividade da carreira docente no Brasil: Relatório Final, São Paulo, 2009.

GILPIN, GREGORY A., Reevaluating the effect of non-teaching wages on teacher attrition, Economics of Education Review, v. 30, pp. 598-616, 2011.

GINTIS, HERBERT, The bounds of reason: Game theory and the Unification of the Behavioral Sciences, Princeton, Princeton University Press, 2009.

GUSTAFSSON, M. AND PATEL, F. Managing teacher pay system: What the local and international data are telling us, Stellenbosh, University of Stellenbosh. Disponível em: http://ideas.repec.org/p/ sza/wpaper/wpapers99.html . Acesso em: 10 mai. 2011, 2008.

HAM, ROGER; JUNANKAR, P. N.; WELLS, ROBERT. Occupational Choice: Personality Matters. IZA: Discussion Paper no. 4105, 2009.

HANUSHEK, E. A. AND RIVKIN, S. G, Teacher quality, In: Hanushek, E. A.; Welch F. (eds.), Handbook of the Economics of Education, Elsevier, v.2, pp. 1052-1078, 2006.

HARRIS, DOUGLAS N.; SASS, TIM R. What makes for a good teacher and who can tell?, National Center for Analysis of Longitudinal Data in Education Research, Working Paper no. 30, 2009.

HERNANI-LIMARINO, W., Are teachers well paid in Latin America and Caribbean? Relative wages and structure of returns of teacher, In: In: Vegas, E. (org.), Incentives to Improve Teaching: Lessons from Latin America, Washington: The World Bank, p.63-150, 2005.

HUMLUM, M. K.; KLEINJANS, K. J.; NIELSEN, H. S., An economic analysis of identity and career choice, Economic Inquiry, v.50, no. 1, pp. 39-61, 2012.

JANN, BENN, A Stata implementation of the Blinder-Oaxaca decomposition, The Stata Journal Working Paper no.5, Swiss Federal Institute of Technology Zurich, 2008.

KUNZE, A. The determination of wages and the gender wage gap: A survey, IZA: Discussion Paper no. $193,2000$.

LIANG, X., Teacher pay in 12 Latin American countries: how does teacher pay compare to other professions, what determines teacher pay, and who are the teachers?, World Bank Human Development Department, LCSDH Paper Series, no. 49, 1999.

LOPEZ-ACEVEDO, G., Teacher's salaries and Professional Profile in Mexico, Working Paper no. 3394, World Bank, Washington-DC, 2004.

MENEZES-FILHO, N.; E. PAZELLO. Do teachers' wages matter for proficiency? Evidence from a funding reform in Brazil, Economics of Education Review, Vol. 26 (6), December, Pages 660-672, 2007. 
MINCER, J., Schooling, Experience and Earnings., National Bureau of Economic Research, New York, 1974.

MIZALA, A.; NOPO, H. Evolution of Teachers' Salaries in Latin America at the Turn of the 20th Century: How Much are they (Under or Over) Paid?). IZA: Discussion Paper no. 6806, 2012. Disponível em SSRN: http://ssrn.com/abstract=2157948.

MIZALA, A.; NOPO, H. Teacher's salaries in Latin America: How much are they (under or over) paid? IZA: Discussion Paper no. 5947, 2011.

MIZALA, A. AND P. ROMAGUERA, Teachers' Salary Structure and Incentives in Chile, In: Vegas, E. (org.), Incentives to Improve Teaching: Lessons from Latin America, Washington: The World Bank, pp.103-151, 2005.

MORICONI, GABRIELA M.. Os professores públicos são mal remunerados nas escolas brasileiras: Uma análise da atratividade de carreira do magistério sob o aspecto da remuneração. 86 f. Dissertação (Mestrado em Administração Pública e Governo), Escola de Administração de Empresas, Fundação Getúlio Vargas, São Paulo, 2008.

OAXACA, R., Male-female wage differentials in urban labor market, International Economic Review, Osaka, v.14, no. 23, pp. 693-709, 1973.

OAXACA, R.; RANSOM, M., On discrimination and the decomposition of wage differentials, Journal of Econometrics, v.61, pp.5-21, 1994.

OCDE. Education at a Glance, 2011. Disponível em http://www.oecd.org.

PIRAS, C. AND SAVEDOFF, W. D., How much do teachers earn?, Working Paper IDB no.375, InterAmerican Development Bank, Washington, D.C, 1998.

PODGURSKY, M. Teacher compensation and collective bargaining, In: Hanushek, E. A.; Machin, S.; Woessman, L. (eds.), Handbook of the Economics of Education (Draft), Elsevier, v.3, pp. 279-313, 2010.

PSACHAROPOULOS, G., VALENZUELA, J. AND ARENDS, M. Teacher Salaries in Latin America: A Review, Economics of Education Review. 15 (4). 401-406, 1996.

RATIER, RODRIGO. Por que tão poucos querem ser professor, Atratividade da carreira docente, Nova Escola, 2010 (229), São Paulo, p. 17, Jan./Fev. 2010. Disponível em: http://www.fvc.org.br/pdf/ atratividade-carreira.pdf. 